\title{
Article
}

\section{Agave Steroidal Saponins as Potential Bioherbicides}

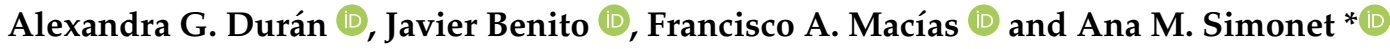 \\ Allelopathy Group, Department of Organic Chemistry, Campus de Excelencia Internacional (ceiA3), Institute of \\ Biomolecules (INBIO), School of Science, University of Cadiz, C/República Saharaui 7, \\ Puerto Real, 11510 Cadiz, Spain; alexandra.garcia@uca.es (A.G.D.); javier.benito@uca.es (J.B.); \\ famacias@uca.es (F.A.M.) \\ * Correspondence: ana.simonet@uca.es; Tel.: +34-956-012765
}

Citation: Durán, A.G.; Benito, J.; Macías, F.A.; Simonet, A.M. Agave Steroidal Saponins as Potential Bioherbicides. Agronomy 2021, 11 2404. https://doi.org/10.3390/ agronomy11122404

Academic Editor: Beatriz Gámiz

Received: 29 October 2021

Accepted: 22 November 2021

Published: 25 November 2021

Publisher's Note: MDPI stays neutral with regard to jurisdictional claims in published maps and institutional affiliations.

Copyright: (c) 2021 by the authors. Licensee MDPI, Basel, Switzerland. This article is an open access article distributed under the terms and conditions of the Creative Commons Attribution (CC BY) license (https:// creativecommons.org/licenses/by/ $4.0 /)$.

\begin{abstract}
Agave saponins are a valuable resource for the prospective development of new forms of agrochemicals. The extraction method was optimized and applied to 17 Agave species. Thirteen saponin fractions (SFs) were assayed on wheat etiolated coleoptiles, and analysed using UPLC-QTOF$\mathrm{MS}^{\mathrm{E}}$, NMR spectroscopy and the HMBC method for aglycone identification (HMAI). Six SFs were assayed on standard target species (STS) and weeds. The new extraction method reduces costs to obtain SFs with the same activity. The tested SFs assayed on etiolated wheat coleoptiles that belong to the subgenus Agave were among those with the highest activity levels. The combination of HMAI together with UPLC-MS allowed the identification of 20 aglycones in the SFs, and no isolation or hydrolysis of the saponins was required. A Principal Component Analysis (PCA) showed that for the active SFs the structural key would be the length of their sugar chain. The presence of a carbonyl group at C-12 implied an enhancement in phytotoxic activity. Six SFs were assayed on seeds, and no activity on Solanum lycopersicum (tomato) was observed; however, good activity profiles were obtained on weed E. crus-galli $\left(\mathrm{IC}_{50}<80 \mathrm{ppm}\right.$ ), better than the commercial herbicide Logran ${ }^{\circledR}$. These findings represent a possible lead for the development of natural herbicides through the use of saponins of subgenus Agave species.
\end{abstract}

Keywords: Agave; saponin; extraction; HMAI; UPLC-MS; phytotoxicity; weed

\section{Introduction}

Plants, because of their lack of mobility and their exposure to biotic and abiotic factors, have developed the most sophisticated chemical communication systems through the production of allelochemicals [1].

Although synthetic herbicides may control weeds in an effective way, not only can they lead to an enhancement in herbicide-resistant weed populations, but they can also present several detrimental effects on the environment and on human health. On the other hand, it has been estimated that without weed control, crop yield losses might scale up to $70 \%[2,3]$. For these reasons, research works on novel, sustainable, effective and more environmentally friendly alternatives for weed management has experienced a considerable increment in the last few years.

In this respect, saponins are some of the products that can be found in nature with a noteworthy chemical composition and biological function [4]. The chemical structure of saponins consists of a hydrophobic backbone (sapogenin or aglycone) and a hydrophilic carbohydrate chain formed by monosaccharide units linked by a glycosidic bond (Figure 1). Depending on their aglycone backbone, they can be classified into two main groups: steroidal (C27) and triterpenoid (C30) saponins [5]. Saponins exhibit antimicrobial, antifungal, insecticidal and antifeeding properties, allowing them to act as a chemical barrier against potential pathogens [4] and, therefore, they represent a valuable resource for the prospective development of new forms of agrochemicals. 


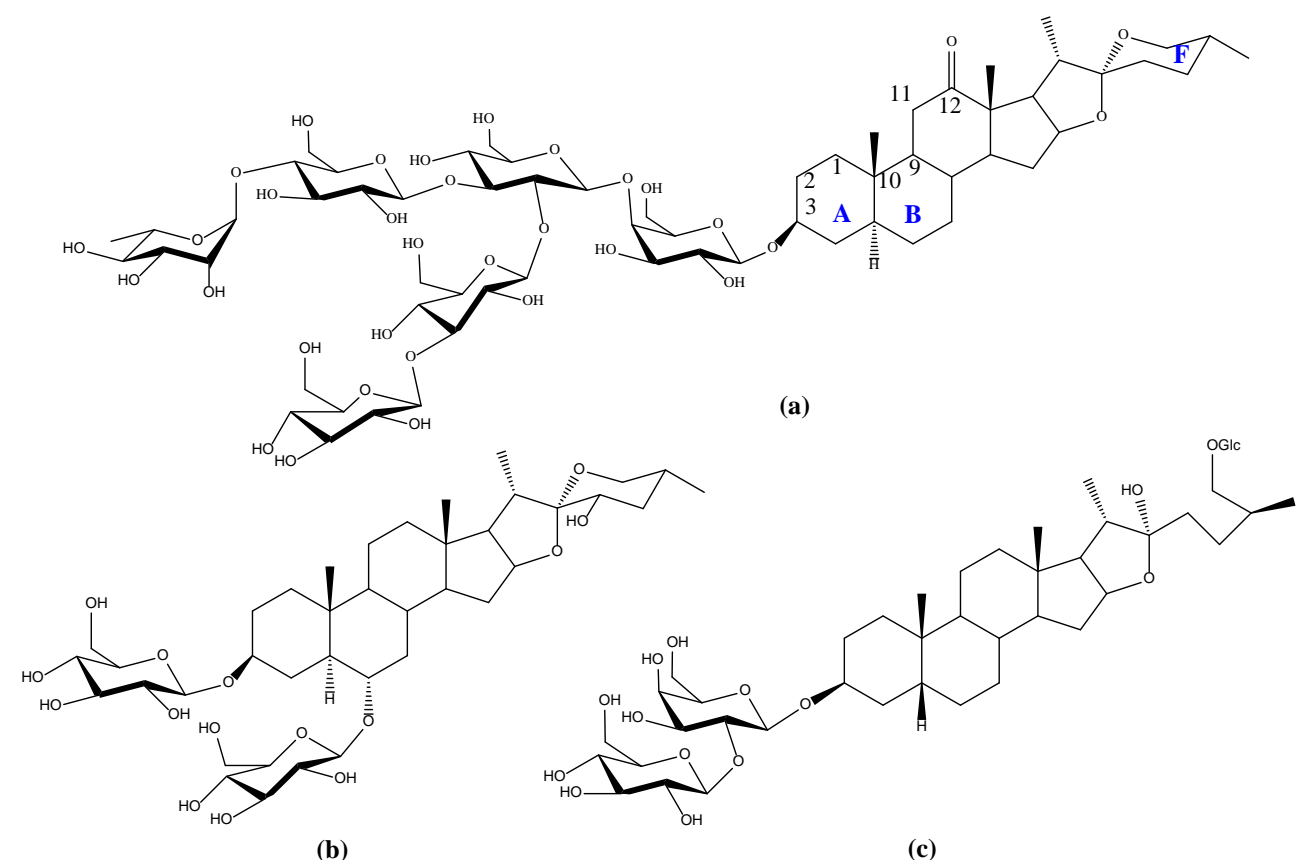

Figure 1. Structure of a monodesmosidic saponin: (a) furcreastatin and two bidesmosidic saponins; (b) cantalasaponin-1; and (c) timosaponin BII.

The phytotoxicity attributed to saponins has been evaluated by several studies that mainly focused on an array of extracts containing these metabolites, such as aqueous, methanolic, ethanolic or $n$-butanol root/shoot extracts from Zea mays, Ziziphus mauritiana var. spontanea Edgew, Oenothera biennis L., Periploca hydaspidis Falc., Bromus pectinatus Thunb, Sapindus mukorossi Gaertn, Erythrina fusca Lour. or Ludwigia hyssopifolia (G. Don) Exell, among others [2,3,6-10].

On the other hand, with regard to the toxicity of the pure compounds on their own, most of the phytotoxicity studies that have been conducted were focused on triterpene saponins [11,12]. Thus, eleven triterpene (oleanane-type) saponins from Microsechium helleri and Sicyos bulbosus (Cucurbitaceae family) roots have been evaluated for phytotoxicity on Lactuca sativa, Solanum lycopersicum, and Lolium perenne. Most of the tested saponins showed significant radicle growth inhibition values, $L$. sativa being the most sensitive species. Heteropappussaponin 7 was one of the saponins with better activity profiles [13]. Other phytochemical research, performed by Stavropoulou and co-workers, described the phytotoxic activity of three triterpene saponins isolated from Bellis longifolia. $\mathrm{IC}_{50}$ values lower than those alleged by regular commercial herbicides when used on duckweed (Lemna paucicostata Hegelm.) were obtained for two of them [14].

The phytotoxicity of certain steroidal saponins has also been evaluated although to a lesser extent. Thus, the saponins isolated from Urochloa humidicola, Agave offoyana or Furcraea hexapetala (Jacq.) Urb. have been reported to exhibit a potent root growth inhibitory activity on L. sativa and on etiolated wheat coleoptiles [15-18]. According to these studies, the presence of oxygenated functional groups in the aglycone backbone and a glycosidic chain with four or more units attached to C-3 are crucial with respect to the saponins' activity [16].

It should also be mentioned that a number of recent investigations have looked into the use of saponins and saponin-rich extracts from quinoa husk as an environmentally friendly method for the preparation of silver nanoparticles with bactericide activity. Segura et al. highlighted the fact that by-products can be used as well as the potential application of silver nanoparticles in agriculture as foliar sprays or plant-growth promoters [19].

The abovementioned studies reinforce the potential use of saponins as saponin-rich fractions or as pure compounds for a sustainable agriculture. 


\section{Materials and Methods}

\subsection{General Experimental Procedures}

Accurate mass was measured on a UPLC-QTOF ESI (Waters Xevo G2, Manchester, UK) high-resolution mass spectrometer (HRESI-TOFMS). The 1D and 2D NMR spectra were recorded on an Agilent INOVA-600 spectrometer equipped with a $5 \mathrm{~mm}{ }^{1} \mathrm{H}-{ }^{13} \mathrm{C}-{ }^{15} \mathrm{~N}$ cryoprobe. Pyridine- $\mathrm{d}_{5}$ (Merck, Darmstadt, Germany) was used as reference solvent and experiments were recorded at room temperature. An amount between 10 and $30 \mathrm{mg}$ of the SFs was used for the NMR experiments. The chemical shifts are given on the $\delta$ scale and are referred to the residual pyridine $\left(\delta_{\mathrm{H}} 8.70,7.55,7.18\right.$ and $\left.\delta_{\mathrm{C}} 149.84,135.60,123.48\right)$.

Methanol and ethanol were supplied by VWR International (Radnor, PA, USA), and $n$-butanol was provided by Panreac Química S.A. (Castellar del Vallés, Barcelona, Spain). TLC silica $60 \mathrm{~F}_{254}$ and TLC Si gel $\mathrm{F}_{254} \mathrm{~S}$ RP-18 were obtained from Merck (Darmstadt, Germany) and used to monitor the obtention of saponin-rich fractions. The compounds were visualized under $\mathrm{UV}_{254 / 366}$ light after spraying them with $\mathrm{H}_{2} \mathrm{SO}_{4}-\mathrm{H}_{2} \mathrm{O}-\mathrm{HOAc}$ $(4: 16: 80 v / v / v)$. SPE Strata-X $33 \mu \mathrm{m}$ polymeric reversed-phase cartridges (Phenomenex) were used to get the SFs.

\subsection{Plant Material}

A leaf from wild Agave americana (1759 g) was collected in Parque Natural de la Bahía de Cádiz (Cádiz, Spain) in November 2015 with GPS coordinates 36.490745, -6.144256.

Moreover, different plant species from the Agavaceae were authenticated and supplied in November 2017 by Desert City S.L. (CIF B86691474, Madrid, Spain). The GPS coordinates were $40.59897539554237,-3.5823863738311497$. Reference samples of powdered plant materials and $n$-ButOH extracts are available in our laboratory, labelled as DC2017-M1-M24.

\subsection{Extraction of Plant Material}

A leaf from wild A. americana was washed with ethanol, and then it was sliced up and dried in an oven at $50{ }^{\circ} \mathrm{C}$ until reaching a constant weight. Finally, it was grinded with a mill, obtaining $217 \mathrm{~g}$ [20].

\subsubsection{Ethanol:Water Macerations}

In total, $2 \mathrm{~g}$ of grinded plant material was extracted with ethanol:water as the extractant $(\times 3)$ and under different extraction conditions (Table S1 in Supporting Information). After each extraction, the vial was centrifuged to get the supernatant and evaporated with a rotatory evaporator, obtaining the hydroalcoholic extract. Then, it was dissolved in $4 \mathrm{~mL}$ of deionized water to carry out a liquid-liquid extraction with $2 \times 2 \mathrm{~mL}$ of $n$-butanol; the organic phase was dried, obtaining the saponin crude extract.

\subsection{2. $n$-Butanol:Water Macerations}

In total, $4 \mathrm{~mL}$ of deionized water were added to $2 \mathrm{~g}$ of grinded plant material. After $2 \mathrm{~h}$, $4 \mathrm{~mL}$ of $n$-butanol were added to proceed with the maceration $(\times 1)$ with different extracting conditions (Table S1 in Supporting information). Then, the vial was centrifuged to filter the liquid and evaporated with a rotatory evaporator, obtaining the saponin crude extract.

\subsubsection{Extraction Scaling via $n$-Butanol:water 1:1 at Room Temperature}

In total, $40 \mathrm{~mL}$ of deionized water were added to approximately $20 \mathrm{~g}$ of grinded plant material to moisturize it. Subsequently, $40 \mathrm{~mL}$ of $n$-butanol were added to perform a maceration for $24 \mathrm{~h}$ under magnetic agitation. The process of obtaining the saponin crude was carried out under the same conditions as above. Another experiment was conducted, obtaining the saponin crude and then adding $40 \mathrm{~mL}$ of deionized water to the maceration and maintaining a mild magnetic agitation for another $24 \mathrm{~h}$. Finally, the liquid was collected and both phases were separated in a separating funnel, drying the organic phase under vacuum. 


\subsubsection{Optimized Procedure of Saponin Extraction}

Dried and crushed material of Agave species were moistened for $2 \mathrm{~h}$ by addition of water in a ratio 2:1 $(v / w)$ water:plant material, then adding $n$-butanol in a ratio 1:1 $(v / v)$ water: $n$-butanol to obtain the biphasic solvent $n$-butanol:water at 1:1. Maceration for $24 \mathrm{~h}$ at room temperature followed, and, finally, the recovery of the organic phase by increasing the volume of water and a mild magnetic agitation. Finally, the liquid was collected and both phases were separated in a separating funnel, drying the organic phase under vacuum (Figure 2).

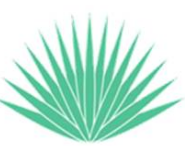

Dried crushed leaves

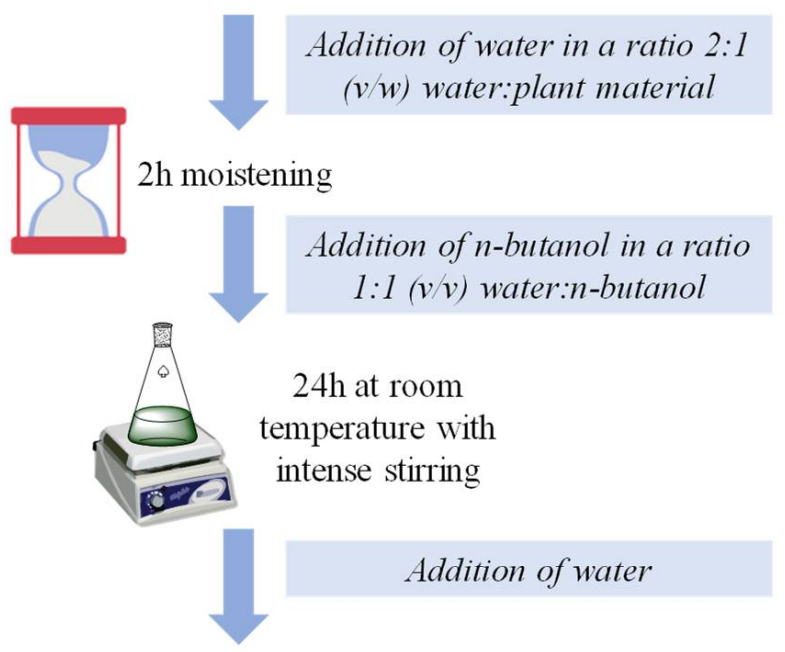

Slow stirring up to $24 \mathrm{~h}$

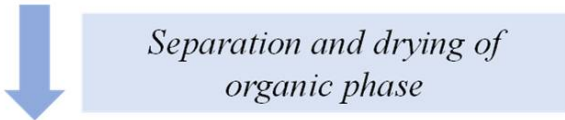

Saponin crude extract

$$
\text { C-18 SPE to get the SF }
$$

Figure 2. Scheme of the optimized extraction method to get the SF.

\subsubsection{Saponin-Rich Extract Preparation}

In total, 20-30 mg of saponin crude was dissolved in $4 \mathrm{~mL}$ of deionized water and then chromatographed with a C-18 SPE cartridge previously conditioned with $10 \mathrm{~mL}$ of methanol, followed by $10 \mathrm{~mL}$ of deionized water. The eluents utilized were $4 \mathrm{~mL}$ of deionized water (sugar fraction), $3 \mathrm{~mL}$ of methanol:water 8:2 (saponin fraction) and $8 \mathrm{~mL}$ of methanol (less polar fraction). 


\subsection{UPLC-QTOF/MS ${ }^{E}$ Analysis}

A UPLC-QTOF ESI (Waters Xevo G2, Manchester, UK) high-resolution mass spectrometer (HRESI-TOFMS) was used to measure the accurate mass and analysis of saponins of the different extracts. An analysis procedure was performed using the methodology described in previous work [21]. Sample solutions $(5 \mu \mathrm{L})$ were injected into an Acquity UPLC HSS T3 $1.8 \mu \mathrm{m}, 2.1 \times 5 \mathrm{~mm}$ VanGuard precolumn attached to an Acquity UPLC HSS T3 $1.8 \mu \mathrm{m}, 2.1 \times 100 \mathrm{~mm}$ column, maintained at $45^{\circ} \mathrm{C}$. The mobile phase consisted of water (A) and acetonitrile (B), each containing $0.1 \%(v / v)$ formic acid, with the following gradient: $0-0.5 \mathrm{~min}, 60 \% \mathrm{~A} ; 0.5-6.0 \mathrm{~min}, 60-50 \% \mathrm{~A} ; 6.0-7.0 \mathrm{~min}, 50-95 \% \mathrm{~A} ; 7.0-7.5 \mathrm{~min}, 95 \% \mathrm{~A}$; $7.5-8.0 \mathrm{~min}, 95-60 \% \mathrm{~A}$, and maintenance in $60 \% \mathrm{~A}(8.0-10.0 \mathrm{~min})$ to condition the column for the next injection. The flow rate was established at $0.4 \mathrm{~mL} / \mathrm{min}$. The temperature in the autosampler was set at $10^{\circ} \mathrm{C}$.

Electrospray Ionization in the negative polarity mode (ESI') was used with the following settings: sample probe capillary voltage $2800 \mathrm{~V}$, sampling cone voltage $30 \mathrm{~V}$, source temperature $120^{\circ} \mathrm{C}$ and desolvation temperature $450{ }^{\circ} \mathrm{C}$. Desolvation and cone gas with flow rates of 850 and $10 \mathrm{~L} / \mathrm{h}$ were used, respectively. The data were acquired in the centroid mode using $\mathrm{MS}^{\mathrm{E}}$ (low collision energy, $6 \mathrm{eV}$; high collision energy ramp, 20-80 eV) over a mass range of $m / z 100-2000$ and a retention time range of $0-10.0$ min with a $0.5 \mathrm{~s}$ scan time. Data acquisition and processing were carried out with MassLynx version 4.1 (Waters Inc. Milford, MA, USA, 2013). The stock solutions (1000 ppm) of the saponin-rich fraction were prepared in water:acetonitrile (6:4). All the samples were injected as a dilution 1:15 $(66.7 \mathrm{ppm})$ and filtered through a PTFE syringe filter $(0.22 \mu \mathrm{m})$ prior to analysis.

\subsection{Identification of Aglycones Using HMAI (HMBC Method for Aglycone Identification) Method}

Two flowcharts (Figures S1 and S2 in Supporting Information) [5] were used as a tool for the identification of the aglycones of the saponins from the Agave species. The decisions (inside diamonds) are named with $\mathrm{D}$ or $\mathrm{S}$ and an integer number, and they use both ranges of chemical shifts and absolute values in the flowchart. In this last case, values within the error range established $\left( \pm 0.4 \mathrm{ppm}\right.$ for ${ }^{13} \mathrm{C}$ NMR and $\pm 0.04 \mathrm{ppm}$ for ${ }^{1} \mathrm{H} \mathrm{NMR}$ in methyl group) for signals were considered. HMBC spectra (Figures S6-S18) were done and referenced to deuterated pyridine $\left(7.55 \mathrm{ppm}\right.$ and $135.6 \mathrm{ppm}$ for ${ }^{1} \mathrm{H}$ and ${ }^{13} \mathrm{C}$ NMR, respectively). Prior signals assignment is not needed and only methyl proton signals (three equivalent protons) were distinguished between $1.6 \mathrm{ppm}$ and $0.5 \mathrm{ppm}$. The flowchart was started with the methyl doublets that provide information on rings $\mathrm{C}-\mathrm{F}$. In some cases, the flowchart indicated that the HMBC values for a specific methyl should be revised. In this situation, taking into consideration the structural features of the remaining methyls, data tables should be used (Tables S2 and S3 in Supporting Information). In a case where the HMBC signals were different to those indicated on the flowchart, the saponin should have other structural characteristics that will require elucidation.

\subsection{Etiolated Wheat Coleoptile Bioassay}

This assay was carried out according to the methodology previously described in the literature [22]. Wheat seeds (Triticum aestivum L. cv. Catervo) were sown in $15 \mathrm{~cm}$ diameter Petri dishes moistened with water and grown in the dark at $22 \pm 1^{\circ} \mathrm{C}$ for 4 days. Coleoptile elongation was measured by the digitalization of the images, and the data were analysed statistically using Welch's test. Saponin-rich fractions were dissolved in DMSO $(0.5 \%$ $v / v)$, and the dilutions were prepared in a phosphate-citrate buffer solution containing $2 \%$ sucrose adjusted to 400, 200, 100, 50, 25, and $12.5 \mathrm{ppm}$. Control samples (buffered aqueous solutions with only DMSO $(0.5 \% v / v))$ and the commercial herbicide Logran ${ }^{\circledR}$, a combination of $\mathrm{N}^{2}$-tert-butyl- $\mathrm{N}^{4}$-ethyl-6-methylthio-1,3,5-triazine-2,4-diamine (terbutryn, 59.4\%) and 1-[2-(2-chloroethoxy)-phenylsulfonyl]-3-(4-methoxy-6-methyl-1,3,5-triazin-2yl)urea (triasulfuron, $0.6 \%$ ), were used as internal references under the same conditions as the SFs. 


\subsection{Seedling Bioassays}

The phytotoxicity of the SFs was assayed at 400, 200, 100, 50, and $25 \mathrm{ppm}$. Three Standard Target Species (STS), including the dicots tomato (Solanum lycopersicum L.), cress (Lepydium sativum L.) and lettuce (Lactuca sativa L.), as well as two weed species, barnyardgrass (Echinochloa crus-galli L.) and perenne ryegrass (Lolium perenne L.), were evaluated for this study. This assay was performed as it has been reported in the literature [21,23]. In the same way as for the coleoptile bioassay, the herbicide Logran ${ }^{\circledR}$ was used as the positive control and buffered nutritive aqueous solution with DMSO ( $5 \mu \mathrm{L}$ DMSO solution $/ \mathrm{mL}$ buffer) without any test compound was used as the negative control. The evaluated parameters in this bioassay (germination rate, root length and shoot length) were recorded using Fitomed ${ }^{\circledR}$ software for evaluation of the data and statistical analysis [24].

\subsection{Statistical Analysis}

Data from the etiolated wheat coleoptile and seedling bioassays were fitted to a sigmoidal dose-response model (constant slope), whenever possible, with the GraphPad Prism v. 5.00 software package (GraphPad, San Diego, CA, USA), also used to calculate $\mathrm{IC}_{50}$ values. Goodness of fit was described by the regression coefficient $\left(\mathrm{R}^{2}\right)$.

Statistical treatment of the data from the Petri dish seedling bioassays was carried out by Welch's test with significance set at 0.01 and 0.05 , expressed by the letters ' $a$ ' and ' $b$ '.

On the other hand, complete linkage cluster analysis was performed based on squared Euclidean distances obtained by using Statistica v. 7.0. software (Tulsa, OK, USA).

\section{Results}

Steroidal saponins are usually found in plants as mixtures that are not easily separated, since they are amphipathic molecules with an aglycone of medium polarity and a sugar chain of high polarity (Figure 1). Therefore, the use of saponin-enriched fractions (SFs) is proposed in this study for their evaluation as potential bioherbicides. The species of the genus Agave are proposed as the source of active saponins.

An efficient method to obtain saponin-rich fractions (SFs) is necessary to screen the bioactive saponins that can be found in Agave species. In order to optimize such an extraction method, leaves from $A$. americana were used as the starting material, since the saponin content described $[25,26]$ for this species includes structural characteristics that suggest that its SF would exhibit phytotoxic activity.

The method that is traditionally used to extract saponins is maceration or solid-liquid extraction using a 70\% hydroalcoholic solution [20]. The extract that is normally obtained contains a large amount of sugars in addition to the saponins, so this is followed by a liquid-liquid extraction with $n$-butanol and water to produce what is known as "crude saponins extract". This extract generally contains sugars and other less polar substances, such as chlorophylls or fatty acids, so it is usually treated for further analysis by performing a solid-phase extraction (SPE) with C-18 as a stationary phase and methanol:water mixtures to obtain three fractions that contain sugars, saponins (SFs) and also less polar substances, respectively.

In the search for less costly alternatives, a series of extractions were carried out by varying the extractant and extraction techniques. All the experiments were performed in duplicate. The first step consisted of adjusting the ethanol:water ratio in the hydroalcoholic solution. For that purpose, four ethanol:water mixtures (10:0, 8:2, 7:3, and 6:4) for $24 \mathrm{~h}$ were used to obtain the hydroalcoholic extracts and saponin fractions (SFs) by SPE (Figure 3). The greatest yield of crude saponins $(4.3 \%)$ with respect to the dry weight of the plant was obtained when an 8:2 ethanol:water solution was employed, and the greatest yield of SFs $(2.1 \%)$ in relation to the dry plant material was obtained after completing the SPE. 


\section{Saponin crude composition}

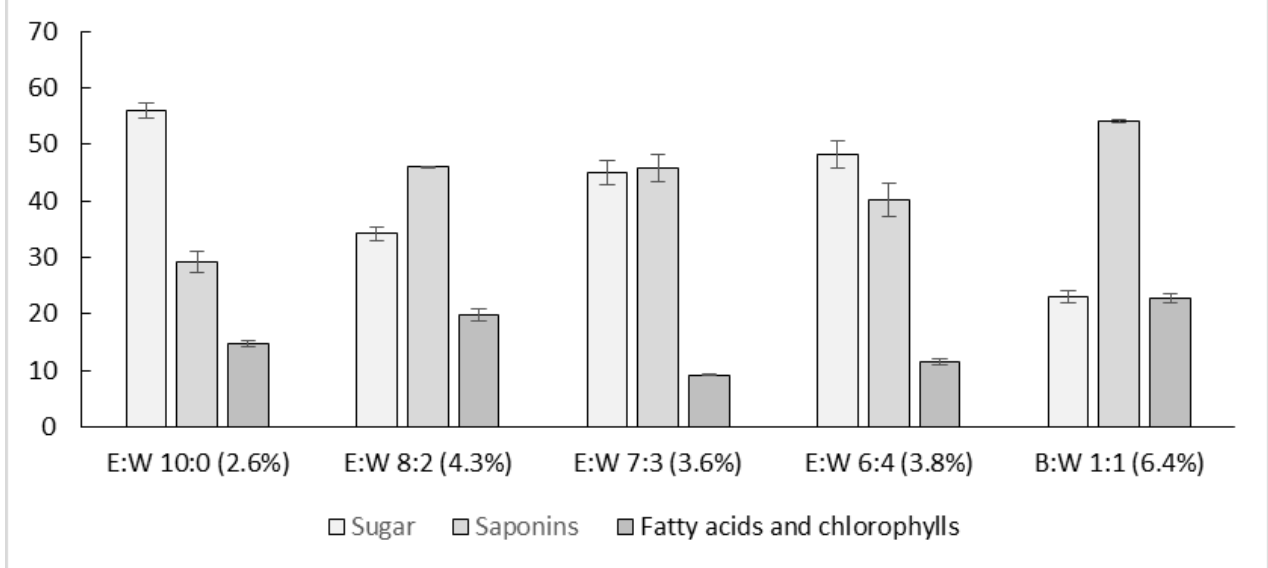

Figure 3. Fractions (\%) of the crude saponin extracts after C-18 SPE. The crude saponin extract yields obtained from A. americana are expressed between parentheses as percentage dry weight (E: ethanol; $\mathrm{W}$ : water; B: $n$-butanol).

Other extraction methods, such as maceration at $50{ }^{\circ} \mathrm{C}$ for two hours or ultrasonic extraction in a bath for $30 \mathrm{~min}$ while using an ethanol:water ratio of 8:2, were tested in order to try and shorten the extraction times. These resulted in lower yields and lower percentages of saponins in the crude saponins extract. On the other hand, sugar extraction was enhanced, particularly when ultrasound was applied (Table S1 in Supporting Information).

The use of the biphasic solvent $n$-butanol:water at 1:1 in order to unify the solid-liquid and liquid-liquid extraction of daidzein from Pueraria lobata has been described before [27]. Given that these solvents are used to obtain the saponin crude, $n$-butanol:water, instead of ethanol:water of 8:2, has been proposed to be used as the extracting solvent for the solidliquid extraction. After the maceration, the two phases were straightforwardly separated, and the organic phase would correspond to the crude saponins extract.

Thus, an extraction method was designed that consisted of a single maceration in $n$-butanol:water at 1:1 and $24 \mathrm{~h}$ at room temperature with magnetic stirring. The same amount of $n$-butanol that was employed for the liquid-liquid extraction in the traditional method was used, so the two methods could be easily compared. The crude saponin extract (Figure 3) not only presented a greater yield (6.4\%) and a higher proportion of saponins $(54.1 \%)$, but it also contained a lesser amount of sugars when compared to the crude obtained through traditional methods. Hence, this method represents a clear improvement of the saponin extraction method, since the hydroalcoholic extraction and the subsequent extract concentration processes could be skipped. We should bear in mind that the same amount of $n$-butanol as in the traditional method had been used.

On the other hand, none of the tested variations concerning the proportions of the biphasic solvent, maceration at $50^{\circ} \mathrm{C}$ for $3 \mathrm{~h}$ or the use of ultrasound for $30 \mathrm{~min}$ improved the yields (Table S1 in Supporting Information). Nonetheless, a slight alteration that did prove useful consisted of the use of the water from the two-phase extractant as a wetting agent for the plant material. After two hours, it was followed by the addition of $n$-butanol, so that the solvents would more easily penetrate into the solid phase.

In order to verify whether the yields obtained would not be affected, the most successful method was scaled up. On the other hand, to simplify the process of separating the organic phase, after extraction the existing volume of water was doubled, and a slow agitation was maintained. This would allow the organic phase to remain on the surface so that it could be collected in just a few hours. Similar yields were obtained as when using either filtering and decantation or centrifugation processes. This procedure only requires basic equipment and reduces the cost of traditional procedures by avoiding the 
hydroalcoholic extraction, the filtering process, the concentration of the organic phase and the liquid-liquid extraction.

The saponin-enriched fractions (SFs) obtained through the best traditional method (ethanol:water 8:2) and the best new method (n-butanol:water 1:1) (Figure 4) were assayed on etiolated wheat coleoptiles. This bioassay is a rapid and simple procedure, whose results are generally related to the phytotoxic activity on model seed assays of the Agave saponins [17]. The activity of the two SFs was rather similar, which would confirm the suitability of the new extraction method.

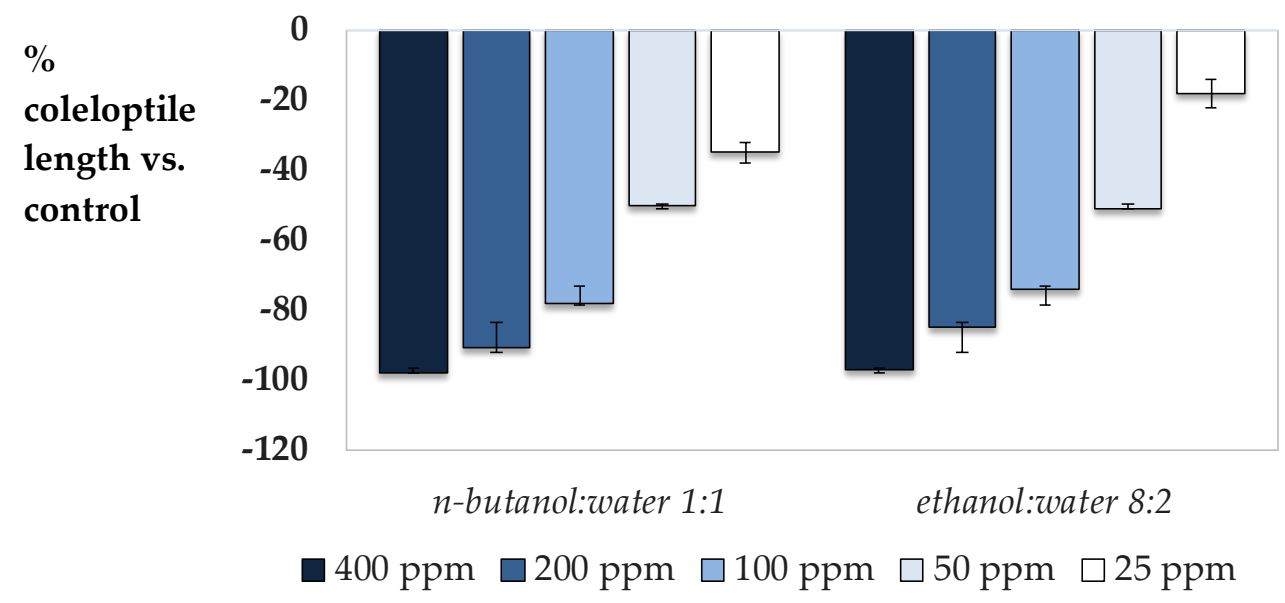

Figure 4. Bioactivity of the SFs by the traditional method (ethanol:water 8:2) and the new method optimized ( $n$-butanol:water 1:1) on etiolated wheat coleoptile bioassay.

Thus, the newly developed extraction method was applied to obtaining the SFs from 17 commercially available Agave species (Table 1) supplied by the Desert City company in Madrid, Spain. The amount of plant material available varied between 281 and $33 \mathrm{~g}$ of fresh leaves and their moisture content varied between 99 and $68 \%$, depending on the species. The crude saponin yields ranged from 1.9 to $7.2 \%$ while the SFs yields ranged from 7.7 to $68.8 \%$. It is interesting to note the wide yield differences between species and between the two extractions that were performed on A. americana. For the testing of the extraction methods, a leaf from an adult wild specimen of $A$. americana was used and the SFs' overall yield was $0.46 \%$ versus the fresh weight, while the leaf provided by Desert City, which was from a young specimen that had been grown under controlled conditions, produced just $0.084 \%$. In sum, it was confirmed that species, plant age and growing conditions are crucial factors with a substantial influence on the amount of extract obtained [28-34].

The $n$-butanol may extract other kinds of compounds, such as polyphenols or organic acids; so, it was necessary to verify whether the SFs mainly contained saponins. For this purpose, their ${ }^{1} \mathrm{H}$ NMR spectra were used; high-field signals in agreement with the aglycones and low-field signals corresponding to the sugar chains were searched for. The four extracts from A. cupreata, A. nigra, A. celsii and A. stricta were discarded at this point, as no clearly distinctive saponin signals were observed (Figures S3-S5 in Supporting Information).

The remaining thirteen species were assayed on etiolated wheat coleoptiles. The highest concentration level tested was $200 \mathrm{ppm}$ as the results from the first bioassay indicated that, at this concentration, the inhibitory activity was close to $100 \%$. The results obtained from the inhibitory activity tests (Figure 5) revealed a group of active SFs with $\mathrm{IC}_{50}$ values between 18.78 and $130.70 \mathrm{ppm}$ and a second group of SFs with no relevant activity. It should be pointed out that all the tested species that belong to the subgenus Agave (A. americana, A. parrasana, A. macroacantha, A. colorata, A. parryi, A. weberi) were among those with the highest activity levels, while those species from the subgenera Littaea presented either a lower activity level (A. geminiflora, A. lophantha) or no relevant activity (A. xylonacantha, A. bracteosa, A. victoria-reginae, A. fernandi regis, A. triangularis) [35]. 
Table 1. Data of the extracts obtained of the different Agave species studied.

\begin{tabular}{|c|c|c|c|c|c|}
\hline Specie & Fresh Weight (g) & Humidity (\%) & $\begin{array}{l}\text { Yield } n \text {-Butanol } \\
{\text { Extract }(\%)^{a}}^{\text {a }}\end{array}$ & $\begin{array}{l}\text { Yield Saponin-Rich } \\
\text { Fraction }(\%)^{b}\end{array}$ & Global Yield (\%) ${ }^{c}$ \\
\hline \multicolumn{6}{|l|}{ Subgenus Agave } \\
\hline $\begin{array}{l}\text { Wild Agave } \\
\text { americana }\end{array}$ & 1759 & 86.6 & 6.4 & 54.1 & 0.460 \\
\hline Agave americana & 110.1 & 91.8 & 4.4 & 25.0 & 0.084 \\
\hline Agave parrasana & 143.2 & 92.5 & 2.8 & 11.5 & 0.025 \\
\hline Agave macroacantha & 32.8 & 86.8 & 4.6 & 68.8 & 0.418 \\
\hline Agave colorata & 117.2 & 94.2 & 3.7 & 19.0 & 0.040 \\
\hline Agave parryi & 124.7 & 84.9 & 2.9 & 37.5 & 0.158 \\
\hline Agave weberi & 85.1 & 90.4 & 5.1 & 22.0 & 0.107 \\
\hline Agave cupreata & 182.8 & 83.1 & 1.9 & 11.9 & 0.038 \\
\hline \multicolumn{6}{|l|}{ Subgenus Littaea } \\
\hline Agave geminiflora & 60.2 & 77.3 & 6.8 & 42.5 & 0.658 \\
\hline Agave lophantha & 52.8 & 81.5 & 6.4 & 18.8 & 0.226 \\
\hline Agave xylonacantha & 41.1 & 79.6 & 4.5 & 26.7 & 0.245 \\
\hline Agave bracteosa & 125.0 & 78.7 & 5.1 & 54.8 & 0.601 \\
\hline $\begin{array}{c}\text { Agave } \\
\text { victoria-reginae }\end{array}$ & 281.1 & 83.9 & 2.7 & 51.9 & 0.226 \\
\hline Agave fernandi regis & 49.8 & 86.9 & 2.9 & 19.0 & 0.063 \\
\hline Agave triangularis & 71.4 & 99.1 & 4.6 & 23.9 & 0.162 \\
\hline Agave nigra & 81.7 & 86.8 & 5.2 & 12.9 & 0.088 \\
\hline Agave celsii & 38.6 & 91.9 & 7.2 & 7.7 & 0.043 \\
\hline Agave stricta & 41.3 & 68.1 & 6.3 & 27.8 & 0.559 \\
\hline
\end{tabular}

${ }^{\text {a }}$ Yield was calculated with the $n$-butanol extract obtained and regarding the dry plant material before extraction. ${ }^{\mathrm{b}}$ Yield saponin-rich extract was calculated regarding the amount of $n$-butanol extract obtained. ${ }^{c}$ Global yield was calculated with the amount of saponin-rich fraction and regarding the fresh weight plant material.

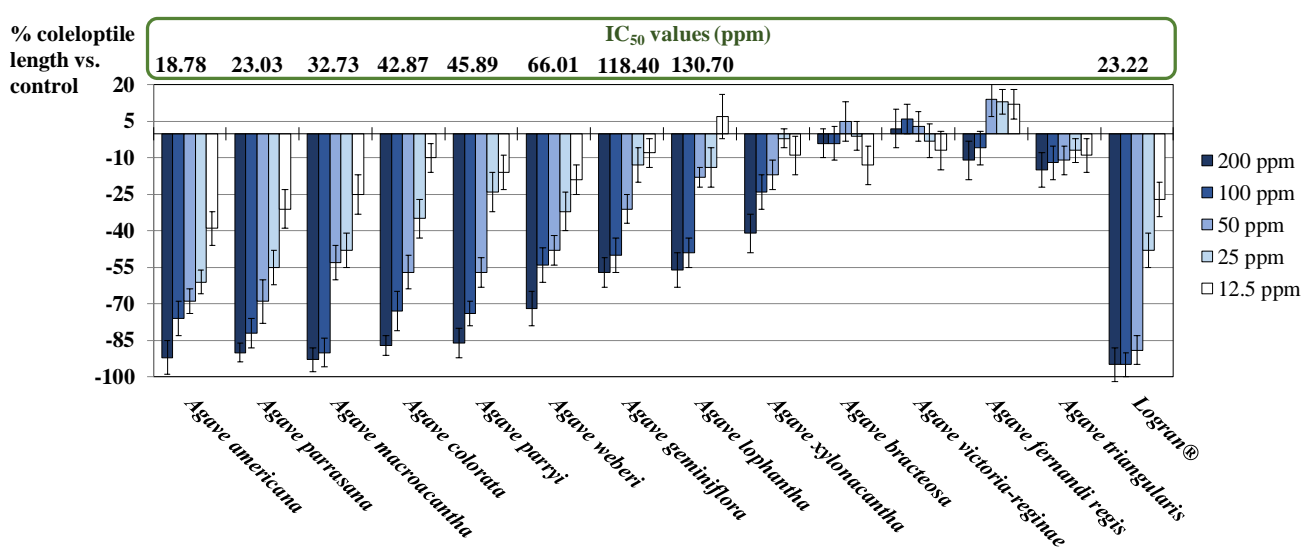

Figure 5. Effect of the saponin-rich fractions (SFs) of the different Agave species on etiolated wheat coleoptiles. Logran ${ }^{\circledR}$ was used as the positive control.

The Structure-Activity Relationship (SAR) analysis performed on the steroidal saponins isolated from species of the Agavaceae family [15-17] suggests that the phytotoxic activity against Lactuca sativa reach the best inhibition values when the saponins have a carbonyl group on the C-12 position of the aglycone as well as four or more units sugar chains attached to $\mathrm{C}-3$. On the other hand, the nature and connections between the monosaccharides seems to be irrelevant. It could, therefore, be considered that the inhibitory activity displayed by the SFs would be attributable to a high content of saponins with the above-described structural characteristics.

Chromatographic analysis using UPLC-QTOF-MS ${ }^{\mathrm{E}}$ analytical techniques combined with the detection of molecular ions and their fragmentation by $\mathrm{MS}^{\mathrm{E}}$ allows to determine the number of sugar units in a saponin as well as the oxygenation and unsaturation of 
the aglycone. Thus, this method was proposed to acquire information on the structural characteristics that are crucial for inhibitory activity, namely, the number of sugar units linked to $\mathrm{C}-3$ and also the oxygenation of the aglycones in the enriched fractions. In our study, we have used the negative mode of detection, with the $\left[\mathrm{M}+\mathrm{HCOO}^{-}\right]^{-}$ion being the most commonly detected. On the other hand, the fractionations observed were those corresponding to the different losses of sugar units, where the base peak of the spectrum from the $\mathrm{MS}^{\mathrm{E}}$ was the fragment corresponding to [Aglycone $\left.-\mathrm{H}+162\right]^{-}$in the case of saponins containing one sugar chain or monodesmosic saponins. The sugar unit directly attached to the aglycone is considered to be a hexose (162 amu) in accordance with the description of Agave saponins [36]. For those saponins with two sugar chains attached to the aglycone or bidesmosic saponins, the $\mathrm{MS}^{\mathrm{E}}$ spectra presented a peak that corresponded to $[\mathrm{M}-\mathrm{H}+162 \times 2]^{-}$, where two hexoses are directly attached to the aglycone. (Figure 6).

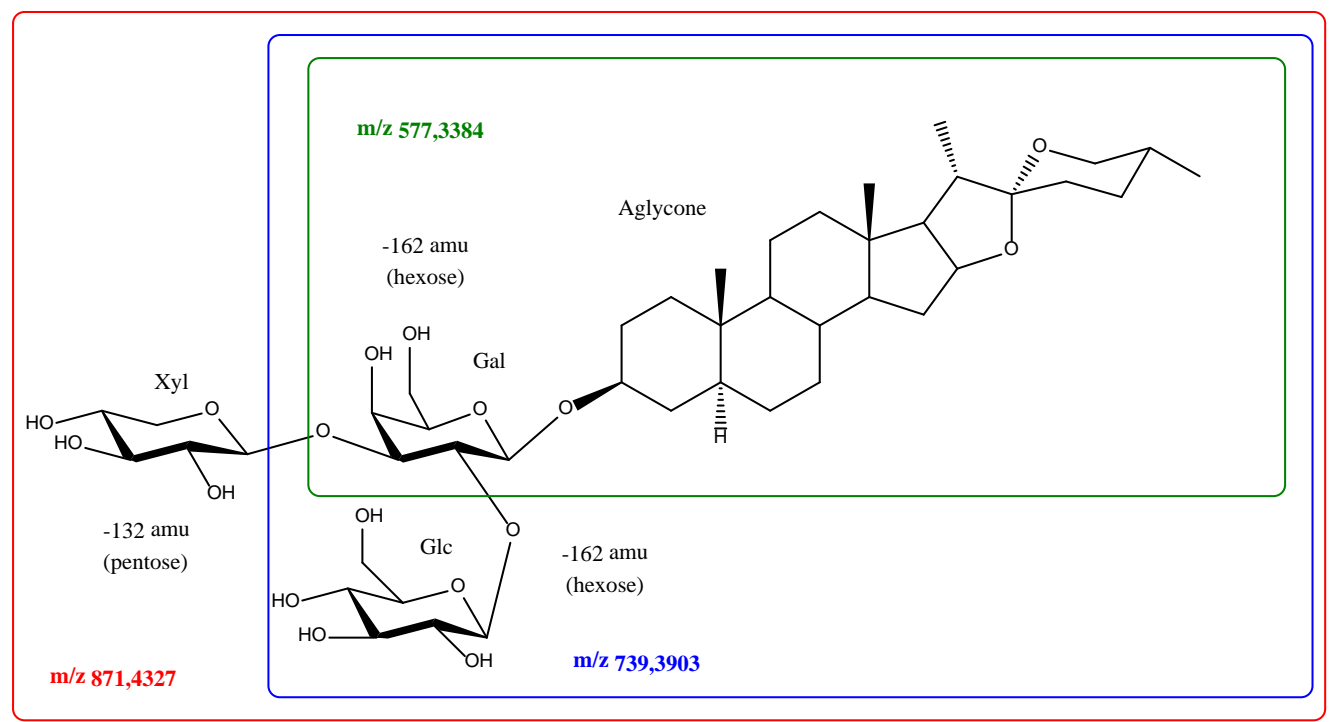

Figure 6. MS/MS losses for a spirostane saponin according to the $\mathrm{MS}^{\mathrm{E}}$ analysis.

The chromatographic method employed was optimized for the separation of monodesmosic saponins, since they are the ones presenting the widest structural diversity in the SFs that have been obtained using this extraction method. The comparison of the chromatograms (Figure 7) from the different species revealed quite distinct patterns in some particular cases. A detailed examination of the molecular ions, as well as of the fragmentation that was observed from the $\mathrm{MS}^{\mathrm{E}}$, allowed us to detect that the bidesmosic saponins appeared mostly when retention times were below $1.40 \mathrm{~min}$. On the other hand, when the base peak of the fragmentation was examined, we could notice that the saponins with the same aglycone and different sugar chains were grouped together. The area of the $\left[\mathrm{M}+\mathrm{HCOO}^{-}\right]^{-}$ions obtained from each saponin was used to determine the percentages of saponins extracted in relation to the total content from each species. The saponins with a percentage higher than 1\% were selected (Table S4 in Supporting Information).

An initial examination of the saponins' retention times seems to indicate that besides the variations related to sugar chains, there are other relevant differences between some of them even if they present the same $\mathrm{m} / \mathrm{z}$ ratio of the fragment corresponding to the aglycone, which indicates the existence of isomeric aglycones (Figure 7). For instance, the saponins with sugar chains with 4 to 6 sugar units and $m / z 591 \mathrm{amu}$ in the [Aglycone $-\mathrm{H}+162]^{-}$ fragment. For species such as A. parrasana, A. parryi, A. colorata, A. macroacantha, A. weberi and $A$. americana, these saponins had retention times between 3.74 and $3.14 \mathrm{~min}$ while for A. lophantha it ranges between 5.03 and $4.68 \mathrm{~min}$. The existence of isomers in Agave saponins is frequent, including structural isomers and stereoisomers, with epimers frequently found on C-5 and C-25 [36]. This is why the information provided by the UPLC-MS analysis is not enough to properly determine which aglycones are present in the enriched fractions. 

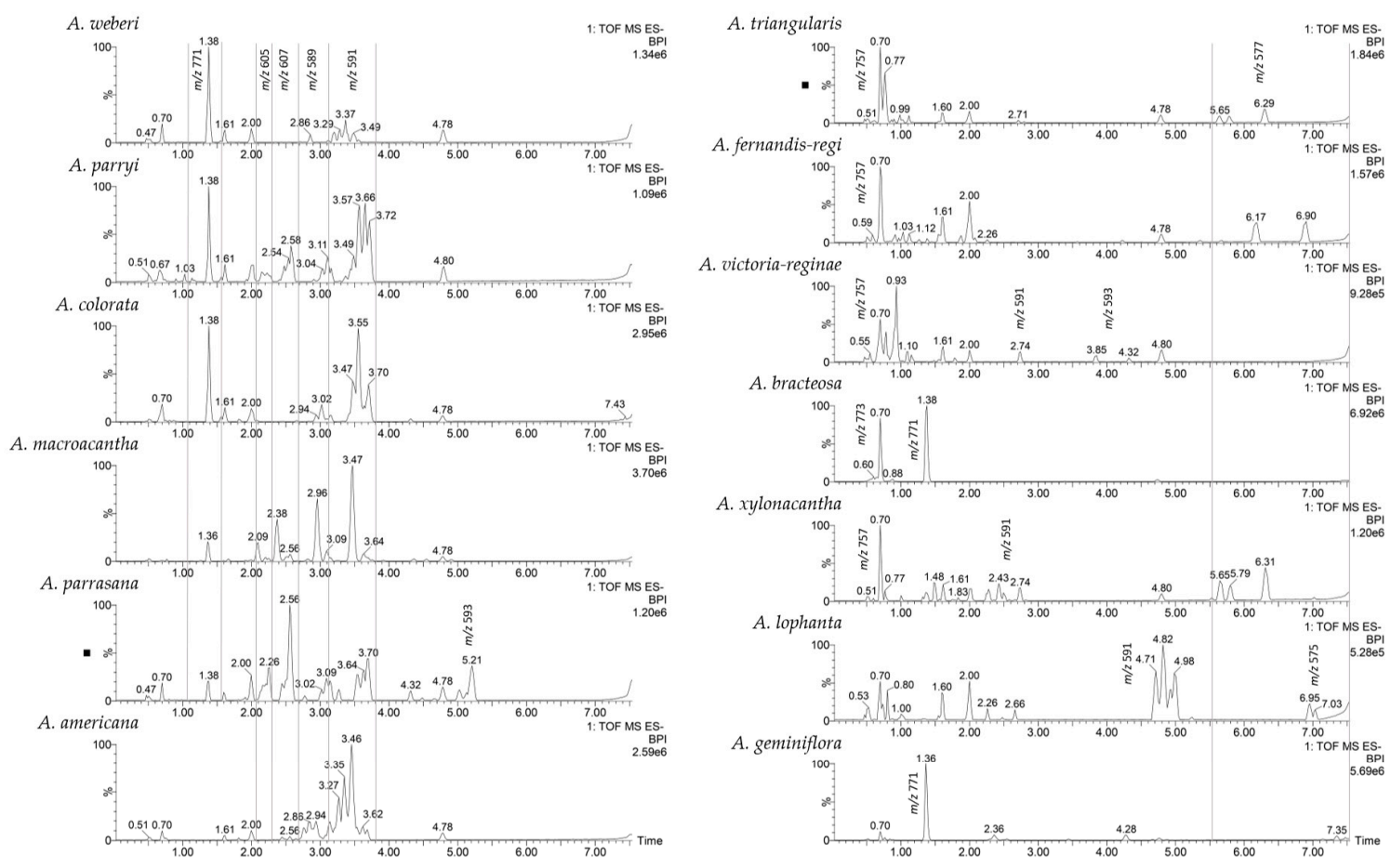

Figure 7. Comparison of the chromatograms of the different SFs obtained.

The HMAI method (HMBC Method for Aglycone Identification) [5] is one of the tools that can be used to identify the structure of the major aglycones present in a mixture of saponins from Agave species. This method uses the ${ }^{1} \mathrm{H}$ and ${ }^{13} \mathrm{C}$ NMR chemical shift values from the HMBC method to determine the nature of the aglycones. Below the procedures to determine the main aglycones in the thirteen SFs tested will be described (Table S5 in Supporting Information). They have been ordered by the value of the fragment corresponding to the aglycone.

\subsection{Monodesmosic Saponins}

\subsection{1. $m / z 577 \mathrm{amu}$}

This fragment (Figure 8) presents a mass consistent with a spirostane aglycone without additional functionalization, and was found in four saponins with retention times between 5.52 and $6.35 \mathrm{~min}$ in the SF from A. xylonacantha (50.6\%). The HMAI method uses the correlations given by HMBC experiment, between methyl protons and carbons that are separated by two and three bonds. The functionalizations and structural features of the aglycones can be deduced as long as they have been described for Agave species. The correlations of the four methyl signals corresponding to a major aglycone appeared in the $\mathrm{HMBC}$ spectrum of the SF of this species. The most shielded doublet at $0.67 \mathrm{ppm}$ was correlated in the HMBC spectrum with the signals at 29.2 and $66.9 \mathrm{ppm}$, which, according to the HMAI flowchart, were consistent with the signal of the methyl on C-27 (D1) in a spirostane aglycone with $R$-configuration on C-25 (D2). On the other hand, the singlet at $0.92 \mathrm{ppm}$ did not correlate with the ${ }^{13} \mathrm{C}$ NMR signals above $50 \mathrm{ppm}$ (S9) and was therefore assigned to a methyl on $\mathrm{C}-19$ with a cis-fusion $(\mathrm{H}-5 \beta)$ of the rings $\mathrm{A}$ and $\mathrm{B}$. The structural features derived by the HMAI method are in agreement with the presence of (25R)- $5 \beta$-spirostan-3 $\beta$-ol, also known as smilagenin (A1), as the major aglycone [37]. For $A$. triangularis the same correlations in the HMBC as well as comparable retention times in the UPLC-MS were found for this fragment (39.5\%). Therefore, this aglycone is also proposed for three saponins in its SF. 

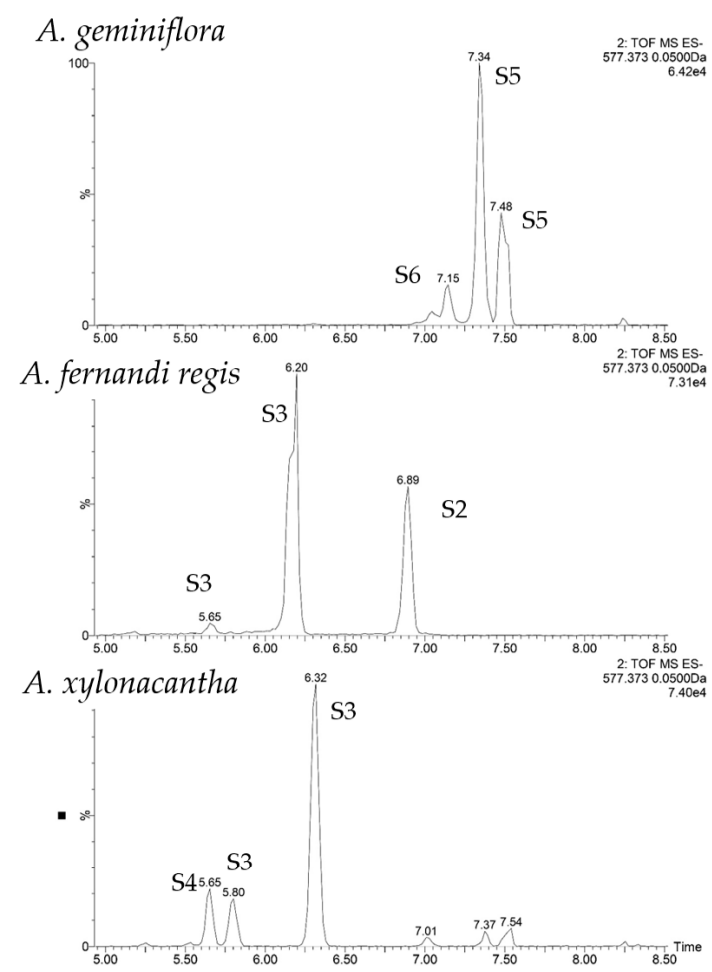

Tigogenin (A3)

\begin{tabular}{ccccc}
\hline $\begin{array}{c}{ }^{1} \mathrm{H} \text { NMR } \\
\text { signal }\end{array}$ & \multicolumn{3}{c}{ HMBC correlations } & $\begin{array}{c}\text { Methyl } \\
\text { assig. }\end{array}$ \\
\hline $1.09 \mathrm{~d}$ (D10) & 41.9 & 62.8 & $109.1(\mathrm{D} 5)$ & $\mathrm{C} 21$ \\
$0.77 \mathrm{~s}$ (S12) & 40.3 & $56.3(\mathrm{~S} 9)$ & $62.8(\mathrm{~S} 11)$ & $\mathrm{C} 18$ \\
$0.64 \mathrm{~d}$ (D2) & $29.1(\mathrm{D} 1)$ & 30.5 & $66.8(\mathrm{D} 1)$ & $\mathrm{C} 27$ \\
$0.60 \mathrm{~s}$ (S18) & $35.6 / 37.1$ & 44.5 & $54.3(\mathrm{~S} 9)$ & $\mathrm{C} 19$ \\
\hline
\end{tabular}

Sarsapogenin (A2)

\begin{tabular}{ccccc}
\hline $\begin{array}{c}\text { 1H NMR } \\
\text { signal }\end{array}$ & \multicolumn{3}{c}{ HMBC correlations } & $\begin{array}{c}\text { Methyl } \\
\text { assig. }\end{array}$ \\
\hline $1.13 \mathrm{~d}$ (D10) & 42.5 & 63.0 & $109.7(\mathrm{D} 5)$ & C21 \\
$1.05 \mathrm{~d}$ (D2) & $26.2(\mathrm{D} 1)$ & 27.7 .5 & $65.1(\mathrm{D} 1)$ & $\mathrm{C} 27$ \\
$0.94 \mathrm{~s}$ (S18) & 30.8 & $35.3 / 36.8$ & $40.1(\mathrm{~S} 9)$ & $\mathrm{C} 19$ \\
$0.78 \mathrm{~s}$ (S12) & 40.6 & $56.4(\mathrm{~S} 9)$ & $63.0(\mathrm{~S} 11)$ & $\mathrm{C} 18$ \\
\hline
\end{tabular}

Smilagenin (A1)

\begin{tabular}{ccccc}
\hline $\begin{array}{c}{ }^{1} \mathrm{H} N M R \\
\text { signal }\end{array}$ & \multicolumn{3}{c}{ HMBC correlations } & $\begin{array}{c}\text { Methyl } \\
\text { assig. }\end{array}$ \\
\hline $1.12 \mathrm{~d}(\mathrm{D} 10)$ & 42.0 & 63.1 & $109.2(\mathrm{D} 5)$ & $\mathrm{C} 21$ \\
$0.92 \mathrm{~s}(\mathrm{~S} 10)$ & $30.7(\mathrm{~S} 10)$ & 35.3 & 36.6 & $\mathrm{C} 19$ \\
$0.79 \mathrm{~s}(\mathrm{~S} 12)$ & 10.6 & 56.1 & $63.1(\mathrm{~S} 11)$ & $\mathrm{C} 18$ \\
$0.67 \mathrm{~d}(\mathrm{D} 2)$ & $29.2(\mathrm{D} 1)$ & 30.7 & $66.9(\mathrm{D} 1)$ & $\mathrm{C} 27$ \\
\hline
\end{tabular}

Figure 8. Chromatograms corresponding to $m / z 577$ amu and the information obtained through the HMAI method.

The $m / z 577$ amu fragment (41.7\%) was also detected through the $\mathrm{MS}^{\mathrm{E}}$ of the A. fernandi regis $\mathrm{SF}$, in three saponins with retention times between 5.67 and $6.90 \mathrm{~min}$. There were no significant differences with respect to the saponins in A. xylonacantha according to the UPLC-MS. The HMBC spectra of its SF also displayed similar correlations, with the exception of a clear difference in the doublet assignable to C-27 according to the HMAI flowchart, given that it showed correlations below $30 \mathrm{ppm}$ and above $60 \mathrm{ppm}$ (D1). The chemical shift of the doublet in the ${ }^{1} \mathrm{H}$ NMR spectrum was $1.05 \mathrm{ppm}$ (D2) and showed no correlations at approximately $75 \mathrm{ppm}$ (D3), which indicates that it corresponds to a spirostane aglycone with $S$-configuration on C-25. The structure of (25S)-5 $\beta$-spirostan-3 $\beta$-ol, named sarsapogenin (A2) is therefore proposed for this aglycone [38].

The $m / z 577 \mathrm{amu}$ fragment also appears in A. geminiflora, although the retention time of the containing saponins ranged between 7.47 and $7.14 \mathrm{~min}$, which indicates that, in this case, it is another isomer. Although in the SF of this species the fragment $m / z 577 \mathrm{amu}$ is not very abundant (9.1\%), its HMBC spectrum does not present correlations that agree with an $\mathrm{H}-5 \beta$ aglycone configuration, while typical $\mathrm{H}-5 \alpha$ configuration correlations appear associated to certain singlets between 0.63 and $0.61 \mathrm{ppm}$. The rest of the correlations were analogous to those of aglycone A1. Therefore, it was concluded that the aglycone is (25R)-5 $\alpha$-spirostan-3 $\beta$-ol, also known as tigogenin (A3) [39].

\subsection{2. $m / z 591 \mathrm{amu}$}

This fragment (Figure 9) was found in most SFs and specifically in A. americana with a percentage of $79.4 \%$. In the ${ }^{1} \mathrm{H}$ NMR spectrum of $A$. americana, four major signals associated to the methyls of a spirostane saponin were observed in the region of the most shielded signals. For the doublet at $0.66 \mathrm{ppm}$ in the HMBC spectrum, correlations appeared at 29.2 and $66.9 \mathrm{ppm}$, which, according to the HMAI flowchart, are consistent with the signal of a methyl on C-27 (D1) in a spirostane aglycone with $R$-configuration on C-25 (D2). On the other hand, the most unshielded doublet would be the signal corresponding to the methyl on C-21, which is confirmed by its correlation with the carbon at 109.4 ppm (D5). 
In addition, the correlation at $54.3 \mathrm{ppm}$ (D5) and the chemical shift of the doublet signal (1.33 ppm (D8)) indicated that the spirostane saponin had a carbonyl group on C-12. A more detailed examination of the most unshielded singlet signal in the ${ }^{1} \mathrm{H}$ NMR spectrum at $1.05 \mathrm{ppm}$ revealed a correlation with a carbon at $212.8 \mathrm{ppm}$ (S1), which confirms the presence of the previously proposed carbonyl group. Finally, a series of singlets between 0.64 and $0.61 \mathrm{ppm}$ presented the same correlations below $60 \mathrm{ppm}$ (S11), which were in agreement with the methyl on C-19 in an aglycone with trans fusion of the rings A and $B$. The structural features that were derived from the HMAI method led us to propose (25R)$3 \beta$-hydroxy- $5 \alpha$-spirostan-12-one, also known as hecogenin (A4), as the major aglycone in the SF from A. americana [40].

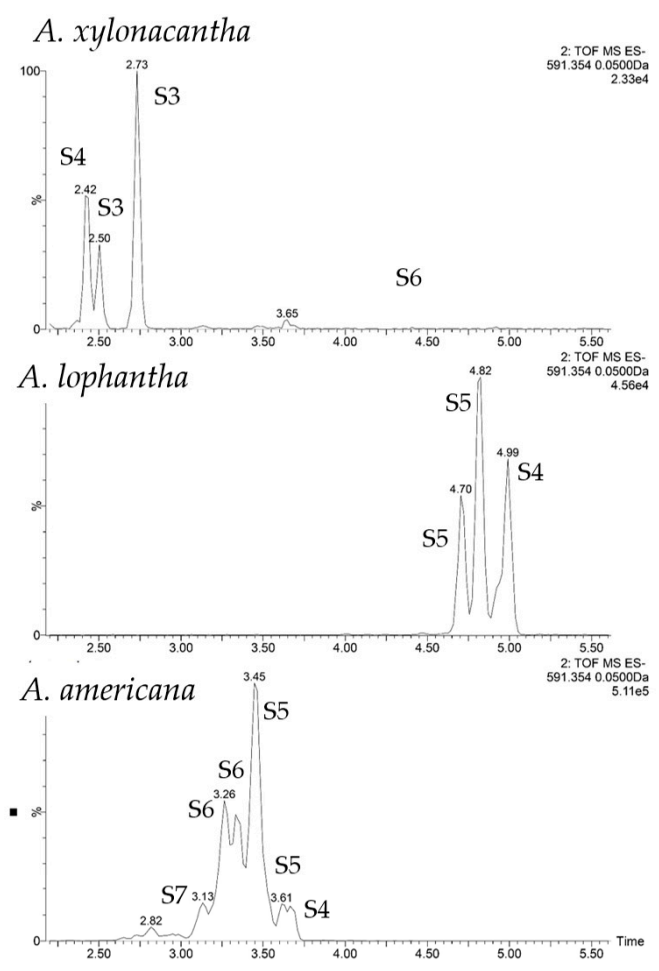

Gloriogenin (A6)

\begin{tabular}{ccccc}
\hline $\begin{array}{c}{ }^{1} \mathrm{H} \text { NMR } \\
\text { signal }\end{array}$ & \multicolumn{2}{c}{ HMBC correlations } & $\begin{array}{c}\text { Methyl } \\
\text { assig. }\end{array}$ \\
\hline $1.34 \mathrm{~d}$ (D8) & 42.6 & $54.3(\mathrm{D} 6)$ & $109.3(\mathrm{D} 5)$ & $\mathrm{C} 21$ \\
$1.05 \mathrm{~s}(\mathrm{~S} 2)$ & 54.3 & 55.8 & $213.1(\mathrm{~S} 1)$ & $\mathrm{C} 18$ \\
$0.93 \mathrm{~s}(\mathrm{~S} 10)$ & $30.7(\mathrm{~S} 10)$ & $35.3 / 36.6$ & 42.0 & $\mathrm{C} 19$ \\
$0.67 \mathrm{~d}(\mathrm{D} 2)$ & $29.2(\mathrm{D} 1)$ & 30.7 & $66.9(\mathrm{D} 1)$ & $\mathrm{C} 27$ \\
\hline
\end{tabular}

Yuccagenin (A5)

\begin{tabular}{llllc}
\hline $\begin{array}{c}{ }^{1} \mathrm{H} \mathrm{NMR} \\
\text { signal }\end{array}$ & \multicolumn{2}{c}{ HMBC correlations } & $\begin{array}{c}\text { Methyl } \\
\text { assig. }\end{array}$ \\
\hline $1.10 \mathrm{~d}(\mathrm{D} 10)$ & 42.0 & 62.8 & $109.3(\mathrm{D} 5)$ & $\mathrm{C} 21$ \\
$0.90 \mathrm{~s}(\mathrm{~S} 6)$ & 37.9 & $45.7 / 50.2$ & $140.1(\mathrm{~S} 6)$ & $\mathrm{C} 19$ \\
$0.78 \mathrm{~s}(\mathrm{~S} 12)$ & 40.2 & 56.5 & $62.8(\mathrm{~S} 11)$ & $\mathrm{C} 18$ \\
$0.66 \mathrm{~d}(\mathrm{D} 2)$ & $29.2(\mathrm{D} 1)$ & 30.7 & $66.9(\mathrm{D} 1)$ & $\mathrm{C} 27$ \\
\hline
\end{tabular}

Hecogenin (A4)

\begin{tabular}{lllll}
\hline $\begin{array}{c}\text { 1H NMR } \\
\text { signal }\end{array}$ & \multicolumn{3}{c}{ HMBC correlations } & $\begin{array}{c}\text { Methyl } \\
\text { assig. }\end{array}$ \\
\hline $1.33 \mathrm{~d}(\mathrm{D} 8)$ & 42.7 & $54.3(\mathrm{D} 6)$ & $109.4(\mathrm{D} 5)$ & $\mathrm{C} 21$ \\
$1.05 \mathrm{~s}(\mathrm{~S} 2)$ & 54.2 & 55.6 & $212.8(\mathrm{~S} 1)$ & $\mathrm{C} 18$ \\
$0.66 \mathrm{~d}(\mathrm{D} 2)$ & $29.2(\mathrm{D} 1)$ & 30.6 & $66.9(\mathrm{D} 1)$ & $\mathrm{C} 27$ \\
$0.62 \mathrm{~s}(\mathrm{~S} 18)$ & 36.4 & 44.5 & $55.5(\mathrm{~S} 11)$ & $\mathrm{C} 19$ \\
\hline
\end{tabular}

Figure 9. Chromatograms corresponding to $m / z 591 \mathrm{amu}$ and the information obtained through the HMAI method.

The signals corresponding to the methyls in hecogenin that were displayed in the ${ }^{1} \mathrm{H}$ NMR spectrum correspond to the saponins with the same aglycone, hecogenin, and different sugar chains. The methyl groups that were more distant from position C-3 were not affected; thus, the doublet signals corresponding to C-27 and C-21 present the same chemical shift. On the other hand, the singlets, $C-18$, and especially $C-19$, which are located between the rings $\mathrm{A}$ and $\mathrm{B}$, are notably influenced, so that they appear with different chemical shifts but with the same correlations in the HMBC. This is explained by the fact that the chemical shifts of the carbons separated by two or three bonds from the methyl H-19 are not so sensitive to the nature of the sugar chain [5].

In addition to A. americana, the species from the subgenus Agave, A. parrasana, A. parryi, A. colorata, A. macroacantha, A. weberi and A. geminiflora display the same signals in their HMBC spectra, as well as retention times according to the UPLC-MS in the same range, which is between 3.74 and $3.14 \mathrm{~min}$. Thus, hecogenin (A4) is the aglycone in the major saponins from these species (Table 2).

In the SF from $A$. lophantha the fragment $m / z 591$ appeared in the saponins (84.8\%) with other retention times, between 4.68 and $5.03 \mathrm{~min}$. The HMBC spectrum of the extract also differed from that of $A$. americana, which indicates the presence of a different aglycone. The HMBC spectrum information derived from the most shielded doublet, at $0.66 \mathrm{ppm}$, 
indicated that the aglycone is spirostane with an $R$ configuration on $C-25$, similarly to that of hecogenin (A4). On the other hand, according to the HMAI flowchart, the singlet at $0.90 \mathrm{ppm}$ presented a correlation at $140.1 \mathrm{ppm}$ (S6), which indicates the existence of a double bond between C-5 and C- 6 and an $\alpha$-hydroxyl group at carbon C-2. All these structural features explained the presence of the fragment $m / z 591$ and allowed to determine that the major aglycone in this species is $(2 \alpha, 3 \beta, 25 \mathrm{R})$-spirost-5-ene-2,3-diol, also known as yuccagenin (A5) [15].

Table 2. Variables stablished for the PCA analysis. Percentage of aglycones with the same structural features identified by the HMAI method and UPLC-MS analysis.

\begin{tabular}{|c|c|c|c|c|c|c|c|c|c|c|c|c|c|c|c|c|}
\hline \multirow[b]{2}{*}{ Species } & \multicolumn{16}{|c|}{ Aglycones Identified through the HMAI Method and UPLC-MS Analysis } \\
\hline & A1 & A2 & A3 & A4 & A5 & A6 & A7/A8 & A9 & A10/A11 & A12/A13/A20 & A14 & A15 & A16 & A17 & A18 & A19 \\
\hline A. americana & 0.00 & 0.00 & 0.00 & 79.43 & 0.00 & 0.00 & 18.65 & 0.00 & 0.00 & 0.00 & 0.00 & 0.00 & 0.00 & 0.00 & 0.00 & 0.00 \\
\hline A. macroacantha & 0.00 & 0.00 & 0.00 & 39.86 & 0.00 & 0.00 & 25.96 & 17.71 & 7.16 & 5.10 & 0.00 & 0.00 & 0.00 & 0.00 & 0.00 & 0.00 \\
\hline A. colorata & 0.00 & 0.00 & 0.00 & 62.37 & 0.00 & 0.00 & 9.83 & 0.00 & 0.00 & 21.22 & 0.00 & 0.00 & 0.00 & 26.24 & 0.00 & 0.00 \\
\hline A. geminiflora & 0.00 & 0.00 & 8.35 & 1.09 & 0.00 & 0.00 & 0.00 & 7.73 & 0.00 & 69.20 & 0.00 & 13.63 & 0.00 & $\begin{array}{l}2.24 \\
0.00\end{array}$ & 0.00 & 0.00 \\
\hline A. bracteosa & 0.00 & 0.00 & 0.00 & 0.00 & 0.00 & 0.00 & 0.00 & 0.00 & 0.00 & 50.07 & 0.00 & 0.00 & 0.00 & 7.87 & 0.00 & 0.00 \\
\hline A. triangularis & 26.64 & 0.00 & 0.00 & 0.00 & 0.00 & 0.00 & 0.00 & 0.00 & 0.00 & 0.00 & 72.19 & 0.00 & 0.00 & 0.00 & 0.00 & 0.00 \\
\hline A. parryi & 0.00 & 0.00 & 0.00 & 53.44 & 0.00 & 0.00 & 11.17 & 16.09 & 3.86 & 13.59 & 0.00 & 0.00 & 0.00 & 0.00 & 0.00 & 0.00 \\
\hline A. xylonacantha & 41.74 & 0.00 & 0.00 & 0.00 & 0.00 & 16.06 & 0.00 & 0.00 & 0.00 & 0.00 & 39.44 & 0.00 & 0.00 & 0.00 & 0.00 & 0.00 \\
\hline A. fernandi regis & 0.00 & 35.63 & 0.00 & 0.00 & 0.00 & 0.00 & 0.00 & 0.00 & 0.00 & 0.00 & 0.00 & 0.00 & 58.34 & 0.00 & 0.00 & 0.00 \\
\hline A. parrasana & 0.00 & 0.00 & 0.00 & 24.34 & 0.00 & 0.00 & 10.22 & 20.58 & 19.39 & 4.80 & 0.00 & 2.94 & $\begin{array}{l}0.00 \\
0.00\end{array}$ & 0.00 & 13.05 & 0.00 \\
\hline A. weberi & 0.00 & 0.00 & 0.00 & 36.42 & 0.00 & 0.00 & 3.68 & 0.00 & 0.00 & 40.23 & 0.00 & 16.11 & 0.00 & 0.00 & 0.00 & 0.00 \\
\hline A. lophantha & 0.00 & 0.00 & 0.00 & 0.00 & 84.77 & 0.00 & 0.00 & 0.00 & 0.00 & 0.00 & 0.00 & 0.00 & 0.00 & 0.00 & 0.00 & 12.35 \\
\hline A. victoria-reginae & 0.00 & 0.00 & 0.00 & 0.00 & 0.00 & 6.13 & 0.00 & 0.00 & 0.00 & 0.00 & 0.00 & 0.00 & 0.00 & 0.00 & 0.00 & 0.00 \\
\hline
\end{tabular}

In the SFs from $A$. xylonacantha and $A$. victoria reginae the fragment $m / z 591$ also appeared at retention times between 2.43 and $2.74 \mathrm{~min}$. On examining the HMBC spectrum of the former, some correlations were found to be consistent with the presence of a carbonyl group on C-12, such as the signal at $213.1 \mathrm{ppm}$ (S1) that corresponds to a methyl signal on C-18 at 1.05 ppm (S2), or the doublet at 1.34 ppm that presented correlations according with a methyl on C-21 in a spirostane aglycone with a carbonyl on C-12. This aglycone displayed the same functionalization as hecogenin (A4) but a different retention time, so they were proposed to be stereoisomers. The major saponins in this species had a H-5 $\beta$ configuration, so the structure was considered to be (25R)-3 $\beta$-hydroxy-5 $\beta$-spirostan-12-one, also known as gloriogenin (A6) [41,42].

Saponins with aglycones of the $H-5 \beta$ series (A1, A6) displayed a shorter retention time than the saponins of the $\mathrm{H}-5 \alpha$ series (A3, A4).

\subsection{3. $m / z 589 \mathrm{amu}$}

This fragment was detected through the $\mathrm{MS}^{\mathrm{E}}$ of the SFs from all the species of the Agave subgroup that were analysed (A. americana, A. parrasana, A. parryi, A. colorata, A. macroacantha and $A$. weberi), at percentages between $26 \%$ and $4 \%$, and with retention times ranging between 2.77 and $3.16 \mathrm{~min}$. Taking into account that the major aglycone in all these species was hecogenin (A4), it is proposed that this fragment would correspond to a hecogeninbased aglycone with an additional unsaturation as a double bond. The HMAI method [5] provides decisions that facilitate the detection of the double bonds that have been described in Agave saponins until present, even when they are found as a minority, since they are located in well differentiated areas of the HMBC spectrum. On the one hand, the singlet corresponding to the methyl on C-19 is located three bonds away from C-9 and C-5, where double bonds are usually found. Thus, when the aglycone presents a double bond between C-9 and C-11, the correlation of a singlet with 170 and 171 ppm in the HMBC spectrum is symptomatic of this, while if it is found between 140 and $141 \mathrm{ppm}$, it is indicative of a double bond between C-5 and C-6. Furthermore, a double bond between C-25 and C-27 may be found. According to the HMAI method, this feature would be recognized based on the absence of one of the methyl doublets as well as on the presence of two singlet signals at 4.76 and $4.79 \mathrm{ppm}$ in the ${ }^{1} \mathrm{H}$ NMR spectrum.

A review of the HMBC spectra of the abovementioned species confirmed that there are correlations consistent with double bonded aglycones between C-9 and C-11 and between C-25 and C-27. As an example of the first case, in the SF of A. macroacantha, the fragment 
$m / z 589$ amu was found at $26 \%$. In its HMBC spectrum a singlet appeared at $0.80 \mathrm{ppm}$ with a correlation at $171.3 \mathrm{ppm}$ (S5) corresponding to an aglycone with trans fusion of the rings $\mathrm{A}$ and $\mathrm{B}(\mathrm{H}-5 \alpha)$, a carbonyl group at $\mathrm{C}-12$ and a double bond $\mathrm{C}-9(11)$. In addition, with a similar intensity to that of the previous singlet, the signal from the methyl group on C-18 was found to have a correlation at 204.3 (S3), while the C-21 signal had one at $1.38 \mathrm{ppm}$ (D8). This would corroborate the functionalization that had been determined for the $\mathrm{C}$ ring. This set of signals could be detected with greater or lesser intensity in A. americana, A. macroacantha, A. parrasana and A. parryi and correspond to the aglycone $(3 \beta, 5 \alpha, 25 \mathrm{R})-3$-hydroxyspirost-9(11)-en-12-one (A7) [5,40].

Regarding the HMBC spectrum of $A$. colorata, no correlations appeared between 170 and $140 \mathrm{ppm}$; however, two broad singlets were observed at 4.76 and $4.79 \mathrm{ppm}$ (D14) that could correspond to the hydrogens of an exocyclic double bond to the F ring between C-25 and C-27. In a mixture it is not easy to determine whether the C-27 methyl doublet had disappeared in the ${ }^{1} \mathrm{H}$ NMR spectrum. However, in the HMBC spectra, some correlations of the singlets at 4.76 and $4.79 \mathrm{ppm}$ with the 3-bonded carbons, C-24 (28.9 ppm) and C-26 (65.1 ppm), were observed, which confirmed that all these signals belonged to the spin system of the F ring in the aglycone and the presence of a methylene group at C-25. On the other hand, this structural feature generates a weak but significant shielding of $0.04 \mathrm{ppm}$ in the signal from the methyl on C-21, according to the regularities that have been described for spirostane saponins [5]. Thus, in the ${ }^{1} \mathrm{H}$ NMR spectrum of the SF, the signals corresponding to the methyl on C-21 (1.29 ppm) could be observed close to the signal from the major aglycone A4 (1.33 ppm) with a difference of $0.04 \mathrm{ppm}$. The SFs of A. americana, A. colorata, A. parrasana, A. parryi and A. weberi presented this set of signals in the HMBC spectra, which correlated with the aglycone $(3 \beta, 5 \alpha, 25 R)$-3-hydroxyspirost-25(27)-en-12-one (A8) [43].

The saponins presenting the regioisomeric aglycones A7 and A8 did not exhibit significant differences with regard to their retention times.

\subsection{4. $m / z 607 \mathrm{amu}$}

This fragment was detected at percentages between $21 \%$ and $8 \%$ after the analyses of the A. parrasana, A. parryi, A. macroacantha and A. geminiflora fractions, and their retention times ranged between 2.37 and $2.59 \mathrm{~min}$. It was assumed to be a hecogenin-derived aglycone with an additional hydroxyl group, which would explain the fragment's mass. The HMBC spectrum of A. parrasana (21\%) was selected, since this fragment appeared, after UPLC-MS analysis of its SF, with the second highest intensity. The hydroxyl groups in Agave saponins are usually described on positions C-2, C-6, C-12 and C-23. No correlations were observed in the HMBC spectrum to indicate the possibility of a hydroxyl group being located on one of the last three positions. However, a singlet at $0.69 \mathrm{ppm}$ presented correlations that were in agreement with the spectroscopic data of HMAI [5] for an aglycone such as hydroxylated hecogenin on C-2. The aglycone $(2 \alpha, 3 \beta, 5 \alpha, 25 R)$ 2,3-dihydroxyspirostan-12-one, also known as manogenin (A9), is therefore proposed as responsible for the fragment $m / z 607 \mathrm{amu}[15,17]$.

\subsection{5. $m / z 605 \mathrm{amu}$}

This fragment was identified at percentages between $20 \%$ and $4 \%$ through the analysis of the fractions from A. parrasana, A. parryi, and A. macroacantha, with retention times ranging between 2.37 and $2.59 \mathrm{~min}$. Taking into account the structural characteristics of the previously described aglycones of these species, it is proposed that this fragment could be due to two aglycones, derived from manogenin (A9), with a double bond between C-9 and C-11 or between C-25 and C-27. Specifically, in the UPLC-MS analysis of A. parrasana (20\%), the duplicity of peaks with the same mass and the same fractionation pattern, including $\mathrm{m} / \mathrm{z}$ $605 \mathrm{amu}$, is observed. In addition, the combination of a hydroxyl group at C-2, a carbonyl group at C-12 and a double bond C-9(11) is easily identifiable through the HMAI flowchart based on the correlation at $170.3 \mathrm{ppm}$ (S4) that can be observed for a singlet at $0.85 \mathrm{ppm}$. The 
proposed aglycones for this fragment are $(2 \alpha, 3 \beta, 5 \alpha, 25 R)$-2,3-dihydroxyspirost-9(11)-en-12one (A10) [17,40] and $(2 \alpha, 3 \beta, 5 \alpha, 25 R)$-2,3-dihydroxyspirost-25(27)-en-12-one (A11) [43].

The major saponins in the SF from $A$. macroacantha, which contain the aglycones A4, A7, A9 and A10, have been recently isolated [21], and the structure of the aglycones proposed by the HMAI method has been confirmed. It was found that the chemical shifts of the correlations in the HMBC spectra of SF presented an average deviation of only $0.1 \mathrm{ppm}$ with respect to the signals in the ${ }^{13} \mathrm{C}$ NMR spectra of the pure compounds. It is interesting to note that the presence of the hydroxyl group on C-2 influences the chemical shift of the methyl on C-21 in a very subtle but noticeable way, so that they can be distinguished in the ${ }^{1} \mathrm{H}$ NMR spectrum of the SF from $A$. macroacantha. Thus, the C-21 doublet signals assigned to spirostanes with a carbonyl group on $\mathrm{C}-12$ that appear between 1.40 and $1.30 \mathrm{ppm}$ are representative of the A4, A7-A11 aglycones. The 1D Pure Shift Spectrum (1DPS) can be conveniently used for the study of this area of the ${ }^{1} \mathrm{H}$ NMR spectrum, since the signals appear as singlets (Figure 10).

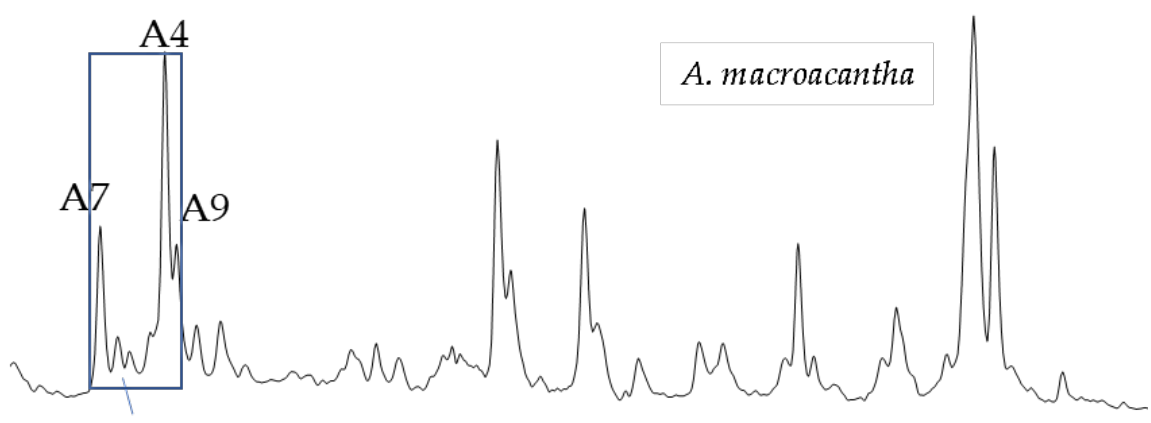

A10
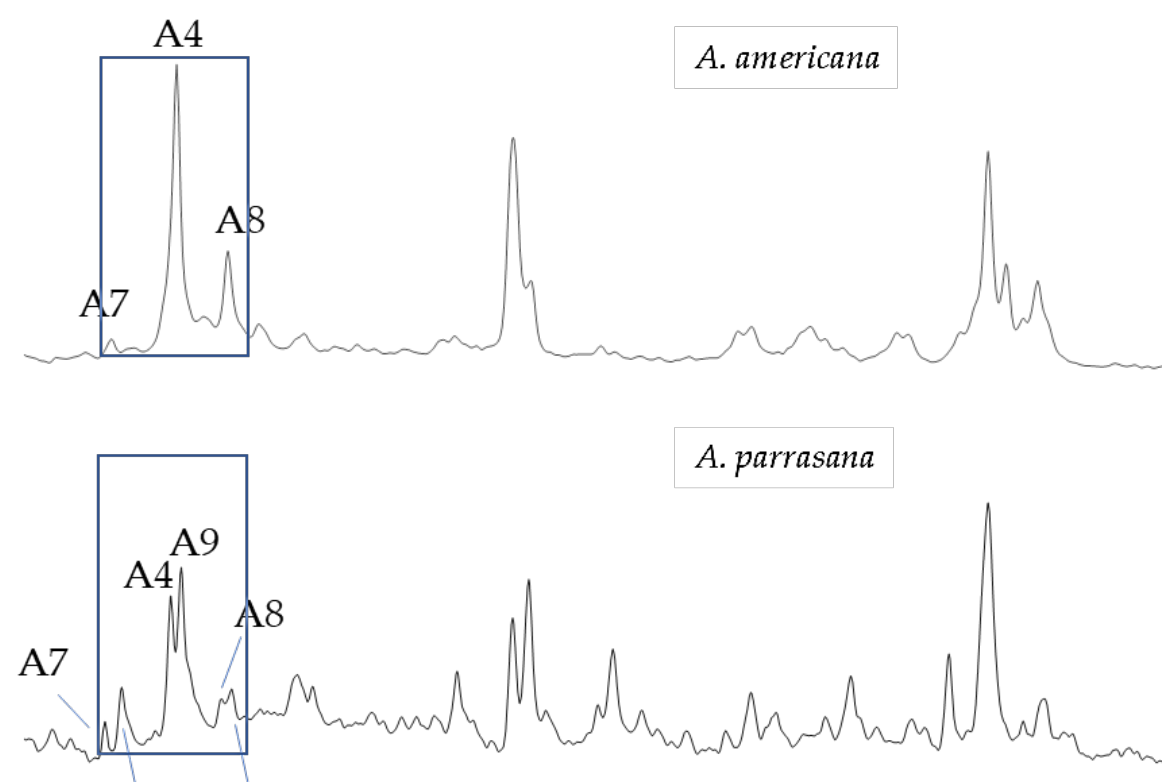

A10 A11

\begin{tabular}{l|l|l|l|l|l|l|l|l|}
1.4 & 1.3 & 1.2 & 1.1 & 1.0 & 0.9 & 0.8 & 0.7 & 0.6
\end{tabular}

Figure 10. PS1D spectra of the SFs of A. macroacantha, A. americana and A. parrasana. Signals that show correlations in HMBC for a C-21 methyl of a spirostane saponin with a carbonyl group at C-12 are within squares. Hecogenin (A4) is the major aglycone. It is observed the deshielding or shielding effect when it also has a double bond at C9(11) (A7) or at C25(27) (A8). Besides, the signals of the methyls C-21 of the hydroxylated derivatives from these three aglycones can be distinguished (A9, A10 and A11). 


\subsection{Bidesmosic Saponins}

3.2.1. $m / z 771 \mathrm{amu}$

This fragment was found in the UPLC-MS analyses of several SFs at two retention times: 0.70 and $1.38 \mathrm{~min}$. Specifically, the latter one corresponded to $[\mathrm{M}-\mathrm{H}]^{-}$and in the $\mathrm{MS}^{\mathrm{E}}$ analysis, minor losses associated to two hexoses were observed. The SF from A. geminiflora presented this fragment at $75 \%$. From the HMBC spectrum, four major signals could be observed corresponding to aglycones. The most significant correlations were those of the doublet at $0.69 \mathrm{ppm}$, which was assigned to the C-27 position in a spirostane aglycone with an $\alpha$-hydroxyl group on C-23. On the other hand, a singlet at $0.57 \mathrm{ppm}$, assigned to the $\mathrm{C}-19$ position, presented correlations with chemical shift values lower than $60 \mathrm{ppm}$ (S11), one of them being $50.7 \mathrm{ppm}$ (S13), which indicated that positions 3 and 6 were oxygenated. The presence of a broad doublet signal at $3.32 \mathrm{ppm}(J=12 \mathrm{~Hz})$, according to the HMAI method, indicated that two glucopyranosyl groups were also located on these positions. This structural combination, including the glucopyranosyl groups, corresponds to cantalasaponin- 1 , a compound whose aglycone is $(3 \beta, 5 \alpha, 6 \alpha, 6 \alpha, 23 S, 25 R)$-spirostan-3,6,23triol or hongguanggenin (A12) [5]. The combination of correlations in the HMBC spectra above described are also found in the following species: A. macroacantha, A. colorata, A. geminiflora, A. parryi, A. parrasana and A. weberi.

During the analysis of the SF from A. bracteosa, an intense peak (56\%) with the same fragmentation and retention time could also be observed. While the HMBC correlations of three of the methyl signals were concordant with aglycone A12, the examination of this spectrum revealed certain differences in the signal from C-27. Its chemical shift did not appear at $0.69 \mathrm{ppm}$, while a doublet appeared at $1.09 \mathrm{ppm}$ with correlations that were not in agreement with the aglycone structural features included in the HMAI method until present. Considering that the structural differences should be located in the $\mathrm{F}$ ring, it could be proposed that it is its epimer on C-25, $(3 \beta, 5 \alpha, 6 \alpha, 6 \alpha, 23 S, 25 S)$-spirostan-3,6,23-triol, also known as paniculogenin (A13). It has already been described [5] that the chemical shifts of the $\mathrm{F}$ ring signals from the $25 \mathrm{~S}$ epimers undergo significant modifications with respect to the $25 R$ ones. It has been specifically described that the signal from C-27 in the ${ }^{1} \mathrm{H}$ NMR is unshielded at $0.38 \mathrm{ppm}$, in our case being $0.37 \mathrm{ppm}$. On the other hand, it was also observed that the ${ }^{13} \mathrm{C}$ NMR signals from C-24, 25 and 26 are shielded to a greater or lesser extent. No saponins with this aglycone have been described in plants from the genus Agave; however, some have been reported in Solanum hispidum [44]. The spectroscopic data described for the saponins of this species were in agreement with those observed in the HMBC spectrum of its SF, so that the structure of the aglycone was confirmed.

The furostane saponins displayed in the UPLC-MS a retention time of approximately $0.70 \mathrm{~min}$. The major [aglycone $-\mathrm{H}+162 \times 2]^{-}$fragments were $\mathrm{m} / z 757$ and $771 \mathrm{amu}$.

\subsection{2. $m / z 757 \mathrm{amu}$}

This fragment appeared in several species at retention time $0.70 \mathrm{~min}$, including $A$. triangularis, where it was particularly abundant (58.7\%). The HMBC spectrum of its SF showed, for a doublet at $0.97 \mathrm{ppm}$ (C-27), correlations at 28.3 and $75.3 \mathrm{ppm}$ (D3), which confirmed that it is a furostane aglycone. On the other hand, the presence of a singlet at $3.25 \mathrm{ppm}$ in the ${ }^{1} \mathrm{H}$ NMR spectrum indicated that the saponins with this aglycone are a methoxylated derivative on C-22. This fact was derived from the use of methanol in the process to obtain the SF [45]. The absence of this solvent in the UPLC-MS allowed the original form of the saponin, with a hydroxyl group on C-22, to be detected. The other major doublet in the fraction was assigned to C-21, whose correlations showed chemical shifts consistent with a methoxylated furostane saponin. On the other hand, two singlets around $0.92 \mathrm{ppm}$ presented correlations with a chemical shift below $50 \mathrm{ppm}$ (S9), which implied that they are signals derived from a methyl group on C-19 located between the rings $\mathrm{A}$ and $\mathrm{B}$ with cis fusion ( $\mathrm{H}-5 \beta)$. Furthermore, the correlation at $30.7 \mathrm{ppm}$ pointed to the absence of a hydroxyl group on the $\mathrm{C}-2$ position. It could finally be deduced that the 
aglycone present in A. triangularis is the furostane derivative of smilagenin (A14) [46]. The same correlations were found in the fraction from A. xylonacantha.

The furostane derivative of tigogenin (A15), which is an epimer of A14 on C-5, was not found as a major form in any of the extracts. However, all the signals that characterize the furostane structure were present in the HMBC spectra of A. geminiflora, A. parrasana and $A$. weberi. In addition, since all the predominant saponins in these species are of the H- $5 \alpha$ series, we propose this aglycone as the one responsible for the presence of the $m / z$ 757 fragment in these species [47].

Another species that presented a high percentage of this fragment was A. fernandiregis (43\%). The correlations observed in the HMBC spectrum resembled those of the aglycone (A14); however, a significant unshielding of the doublet of C-27 was observed, which could be explained by an $S$ configuration of C-25 in this particular case. This hypothesis is supported by the fact that the difference in the chemical shift of H-26 $\left(\Delta_{\mathrm{ab}}=4.07 \mathrm{ppm}-3.5 \mathrm{ppm}\right)$ is $0.57 \mathrm{ppm}$, a typical in $25 \mathrm{~S}$ furostane derivatives. These values could be obtained with the correlation between the signal of $\mathrm{H}-26$ and C-27 showed by the HMBC spectra [48]. Therefore, the furostane derivative from sarsapogenin (A16) [41] is proposed to be the aglycone in this species.

\subsection{3. $m / z 771 \mathrm{amu}$}

In the saponin fraction from $A$ colorata, this fragment $(26.2 \%)$ appeared at $0.70 \mathrm{~min}$ retention time, which differs from the previous fragment $(\mathrm{m} / z 757 \mathrm{amu})$ by $14 \mathrm{amu}$. In the HMBC spectrum it could be detected by a signal at $1.53 \mathrm{ppm}(\mathrm{D} 7)$, assigned to C-21 correlations with ${ }^{13} \mathrm{C}$ NMR signals above $40 \mathrm{ppm}$ (D1), one of these being $110.7 \mathrm{ppm}$ (D5) and $55.2 \mathrm{ppm}$ (D6) another, which, according to the HMAI flowchart, would correspond to a furostane aglycone with a carbonyl group on C-12. Furthermore, the signal at $0.97 \mathrm{ppm}$ presented the typical C-27 correlation of a furostane derivative. Given that the major spirostane saponin in A. colorata is hecogenin (A4), which has a carbonyl group on C-12, this aglycone was considered to be its furostane derivative (A17) [5].

On the other hand, following the same methodology, the structures of some minor aglycones were proposed based on the mass of their characteristic fragment and the functionalization and structural features exhibited by the SFs where they were present. In accordance with the information provided by the HMAI method, as well as with the chemical shifts described in the literature, were proposed: $(2 \alpha, 3 \beta, 5 \alpha, 25 R)$-spirostan-2,3diol, also known as gitogenin (A18) [40], for A. parrasana (13\%); $(3 \beta, 25 R)$-spirost-5-en-3ol, also known as diosgenin (A19) [15,49], for A. lophantha (12.3\%); and $(3 \beta, 5 \alpha, 6 \alpha, 25 R)$ spirostan-3,6-diol, also known as chlorogenin (A20) [15,50], for A. geminiflora $(6.8 \%)$ as well as for A. parrasana (1.73\%).

All the chemical shift values in the HMBC correlations corresponding to each aglycone were compared against those described in the literature, in order to validate our proposal.

Only a few aglycones could not be identified, especially those in A. victoria-reginae, as the correlations that appeared in the HMBC spectra did not exactly match the HMAI flowchart. In such cases, a further isolation of the saponins would be necessary for proper elucidation.

After examining the HMBC spectra of the 13 saponin fractions (SFs) from the Agave species that were considered in this study, using the HMAI method together with the information provided by UPLC-MS, 20 aglycones, including the epimers on positions C- 5 and C-25, were successfully identified (Figure 11). Specifically, the epimeric spirostane saponins on C-5 presented different retention times in the UPLC-MS, while the ones on C-25 did not. Furthermore, the double bonds were located on the C-5(6); C-9(11) and C-25(26) positions. The saponins that contained the two last options presented similar retention times. According to these results, it can be concluded that the combination of HMAI together with UPLC-MS allows the identification of the major aglycones in SFs, and that no isolation or hydrolysis of the saponins is required, regardless of the sugar chains that they may contain. 

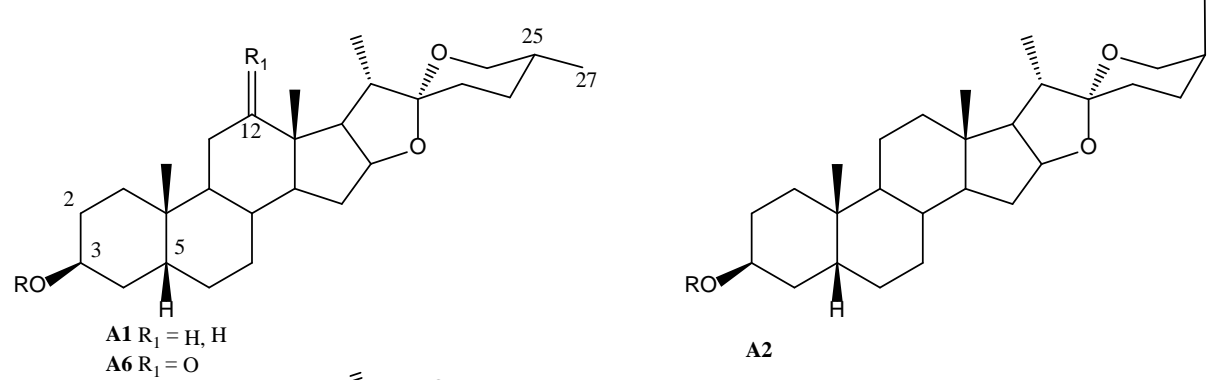

A2
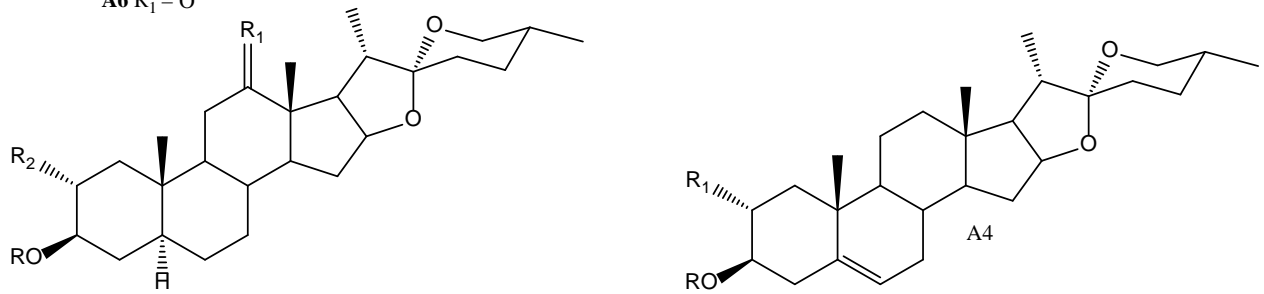

A3 $\mathrm{R}_{1}=\mathrm{H}, \mathrm{H} \mathrm{R} \mathrm{R}_{2}=\mathrm{H}$

A4 $\mathrm{R}_{1}=\mathrm{O} \mathrm{R}_{2}=\mathrm{H}$

A9 $\mathrm{R}_{1}=\mathrm{O} \mathrm{R}_{2}=\mathrm{OH}$

A5 $\mathrm{R}_{1}=\mathrm{OH}$

A18 $\mathrm{R}_{1}=\mathrm{H}, \mathrm{H} \mathrm{R}_{2}=\mathrm{OH}$
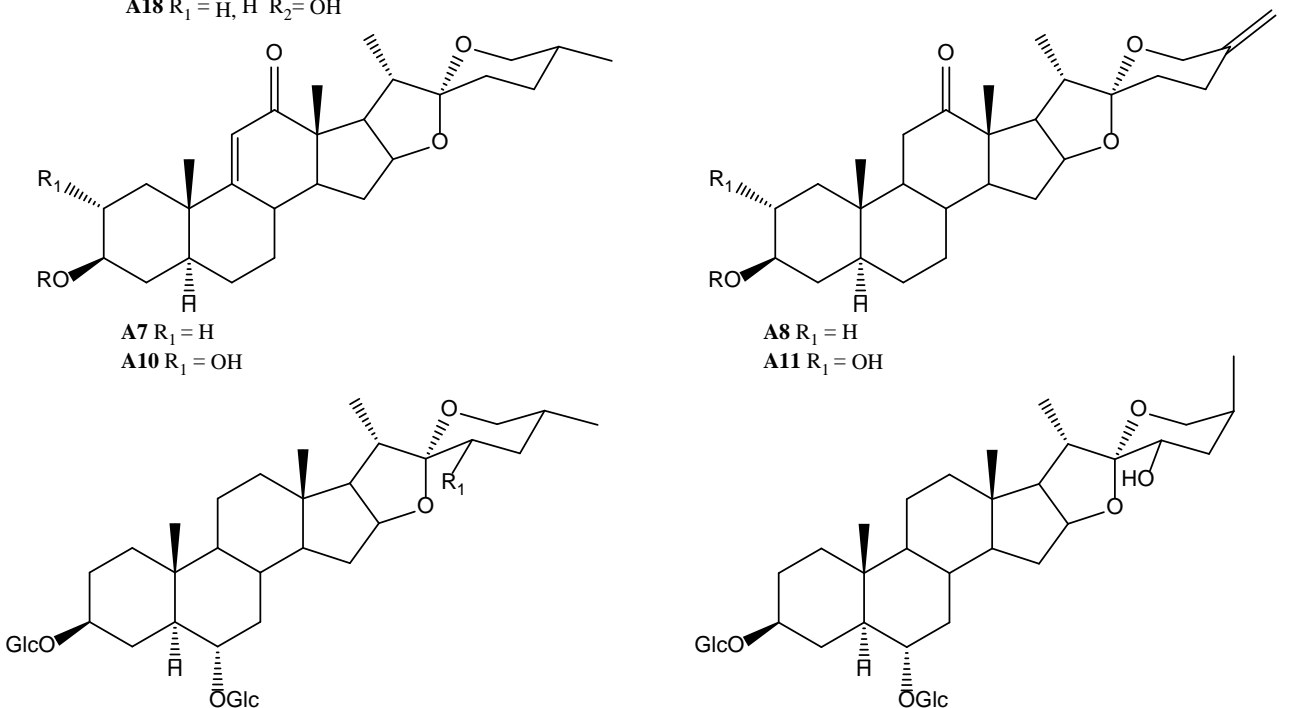

A12 $\mathrm{R} 1=\mathrm{OH}$

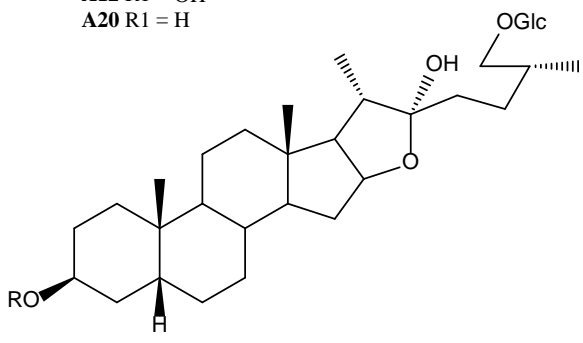

A13
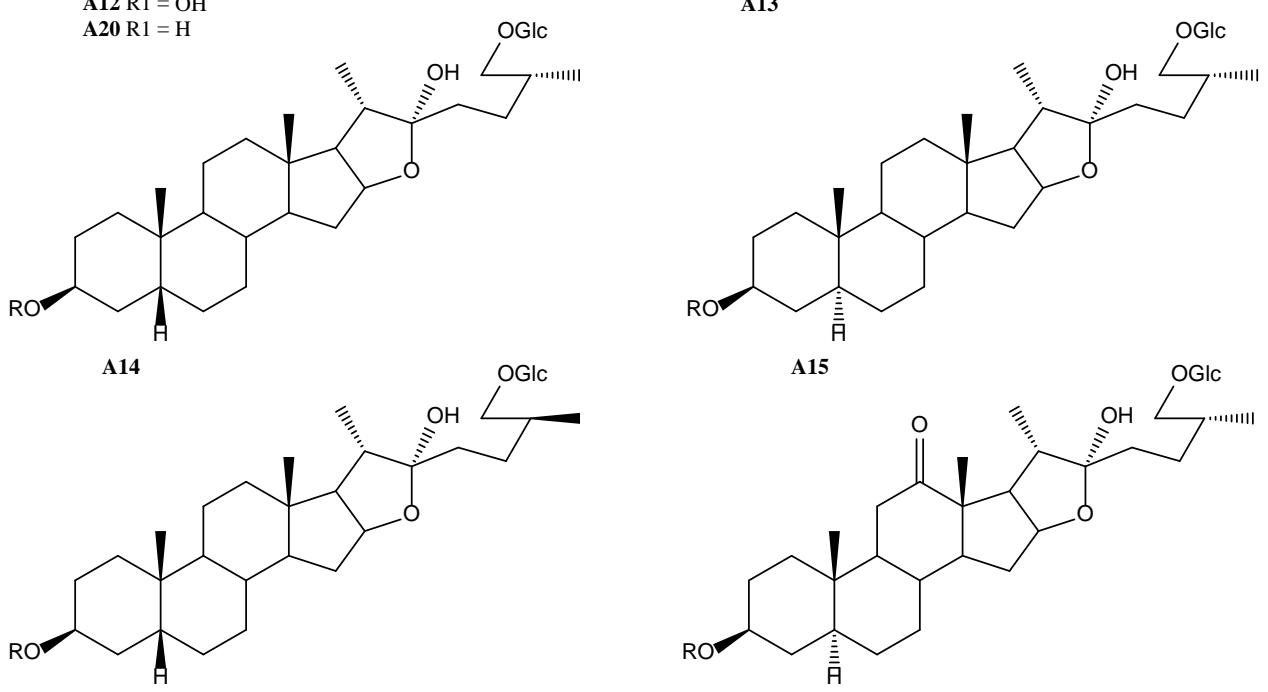

A16

A17

Figure 11. Structure of the spirostane and furostane aglycones identified by the HMAI method in the different SFs from Agavaceae. 


\subsection{SAR Study}

A statistical study was carried out in order to determine any possible correlations between the structural features of the saponins from the different species as well as to verify whether such structural aspects can be related to their biological activity. For this purpose, the sugar chain size, expressed in terms of number of sugars, as well as the different aglycones were established as the parameters to be considered.

The saponins that had been identified in the SFs were divided into three groups as follows: monodesmosic saponins, which have up to seven unit sugar chains on C-3; furostane saponins, derived from the previous ones and with a less structural diversity in their aglycone; and, finally, those containing a hexapyranosyloxy group on C-6 and $\mathrm{C}-3$, such as cantalasaponin- 1 and its derivatives. Specifically, cantalasaponin- 1 has been described in several species of the genus, namely, A. cantala, A. americana [25], A. fourcroydes [50], A. tequilana, A. angustifolia [51], A. macroacantha [52], A. sisalana [53] and A. offoyana [15], which indicates that it is a rather frequent saponin in Agave species. This fact was also confirmed in the course of our study. Regarding the phytotoxic activity levels of the saponins in each of the three groups that have been previously established, according to published studies [15,17], significant values were reported with respect to the saponins in the first two groups; however, cantalasaponin-1 and other analogous molecules did not exhibit any phytotoxic activity.

In this sense, for the statistical study, the relative percentages of each one of the saponins in each SF were calculated based on the intensity of the molecular ions in the UPLC-MS. Moreover, a series of variables related to the structure of the saponins in each SF were defined by grouping the intensities of all the saponins with the same characteristics. Thus, the percentages of all the saponins in the third group were arranged under a single variable called A12, A13, A20. With respect to the saponins in the first and second groups together, the parameters S1 to S7 were used, which were defined as the percentage of saponins with sugar chains with one to seven sugar units linked to C-3. Finally, the aglycone-related variables were gathered under the parameters A1-A19 and Unknow1-7. Given that saponins with aglycone pairs with double bonds on C9(11) and C25(27) cannot be individually differentiated by their retention times, each one of the following pairs was analysed as a whole: A7, A8 and A10, A11 (Tables 2 and 3).

After all the variables were calculated, a Principal Component Analysis (PCA) was performed (Figure 12), where two clusters defined by PC1 could be observed. On the one hand, the sugar chains with up to three sugar units and H-5 $\beta$ aglycones, which were associated to inactive SFs, would be grouped in the quadrants on the right. On the other hand, the active SFs with sugar chains, with at least four sugar units and aglycones with either $\mathrm{H}-5 \alpha$ or a double bond on C5(6), were located in the left quadrants. Thus, it could be confirmed that the phytotoxic activity of the SFs is related to the presence of saponins with sugar chains with four or more sugar units and no H-5 $\beta$ configuration. However, since saponins with this configuration do not usually present long sugar chains, the predominant factor to be considered would be the length of their sugar chain. With respect to the vertical axis defined by the $\mathrm{PC} 2$, the most active $\mathrm{SF}$, corresponding to the subgenus Littaea, namely, A. geminiflora and A. lophantha, appeared at a longer distance from this axis. The saponins that were detected in these two species presented different aglycones, with a minor presence of a carbonyl group on C-12. However, it should also be noted that the most active species, all of which belong to the subgenus Agave, were more closely clustered together, with most of the aglycones presenting a carbonyl group on C-12. Moreover, even though a higher proportion of this functional group implies an enhancement in phytotoxic activity, it was not an essential factor to actually display some phytotoxic activity, as observed in the cases of A. geminiflora and A. lophantha. 
Table 3. Variables established for the PCA analysis. Percentage of saponins with sugar chains with one to seven sugar units linked to C-3 and the percentage obtained for the unknown compounds.

\begin{tabular}{ccccccccccccccc}
\hline & \multicolumn{1}{c}{ \% of Saponins with Sugar Chains Linked to C-3 } & \multicolumn{4}{c}{ Unknown Compounds } \\
\hline Species & \%S1 & $\mathbf{\% S 2}$ & $\mathbf{\% S 3}$ & $\mathbf{\% S 4}$ & $\mathbf{\% S 5}$ & $\mathbf{\% S 6}$ & $\mathbf{\% S 7}$ & $\mathbf{1}$ & $\mathbf{2}$ & $\mathbf{3}$ & $\mathbf{4}$ & $\mathbf{5}$ & $\mathbf{6}$ & $\mathbf{7}$ \\
\hline A. americana & 0.00 & 0.00 & 0.00 & 2.69 & 42.87 & 47.31 & 5.20 & 0.00 & 0.00 & 0.00 & 0.00 & 0.00 & 0.00 & 0.00 \\
A. macroacantha & 0.00 & 0.00 & 0.00 & 4.48 & 86.21 & 0.00 & 0.00 & 0.00 & 0.00 & 0.00 & 0.00 & 0.00 & 0.00 & 0.00 \\
A. colorata & 0.00 & 0.00 & 0.00 & 15.88 & 61.34 & 0.00 & 0.00 & 0.00 & 0.00 & 0.00 & 0.00 & 0.00 & 0.00 & 0.00 \\
A. geminiflora & 0.00 & 0.00 & 0.00 & 3.38 & 23.77 & 3.65 & 0.00 & 0.00 & 0.00 & 0.00 & 0.00 & 0.00 & 0.00 & 0.00 \\
A. bracteosa & 38.03 & 11.10 & 0.00 & 0.00 & 0.00 & 0.00 & 0.00 & 0.00 & 0.00 & 0.00 & 41.27 & 0.00 & 0.00 & 0.00 \\
A. triangularis & 0.00 & 13.15 & 70.98 & 14.70 & 0.00 & 0.00 & 0.00 & 0.00 & 0.00 & 0.00 & 0.00 & 0.00 & 0.00 & 0.00 \\
A. parryi & 0.00 & 0.00 & 0.00 & 26.72 & 57.83 & 0.00 & 0.00 & 0.00 & 0.00 & 0.00 & 0.00 & 0.00 & 0.00 & 0.00 \\
A. xylonacantha & 0.00 & 0.00 & 59.22 & 29.06 & 8.96 & 0.00 & 0.00 & 0.00 & 0.00 & 0.00 & 0.00 & 0.00 & 0.00 & 0.00 \\
A. fernandi regis & 0.00 & 45.61 & 53.57 & 0.00 & 0.00 & 0.00 & 0.00 & 5.21 & 0.00 & 0.00 & 0.00 & 0.00 & 0.00 & 0.00 \\
A. parrasana & 0.00 & 0.00 & 0.00 & 51.34 & 39.19 & 0.00 & 0.00 & 0.00 & 0.00 & 0.00 & 0.00 & 0.00 & 0.00 & 0.00 \\
A. weberi & 0.00 & 0.00 & 0.00 & 0.00 & 16.66 & 39.55 & 0.00 & 0.00 & 0.00 & 0.00 & 0.00 & 0.00 & 0.00 & 0.00 \\
A. lophantha & 0.00 & 0.00 & 0.00 & 23.91 & 73.21 & 0.00 & 0.00 & 0.00 & 0.00 & 0.00 & 0.00 & 0.00 & 0.00 & 0.00 \\
A. victoria-reginae & 34.53 & 17.98 & 46.02 & 0.00 & 0.00 & 0.00 & 0.00 & 0.00 & 7.05 & 2.05 & 0.00 & 22.64 & 34.53 & 26.15 \\
\hline
\end{tabular}

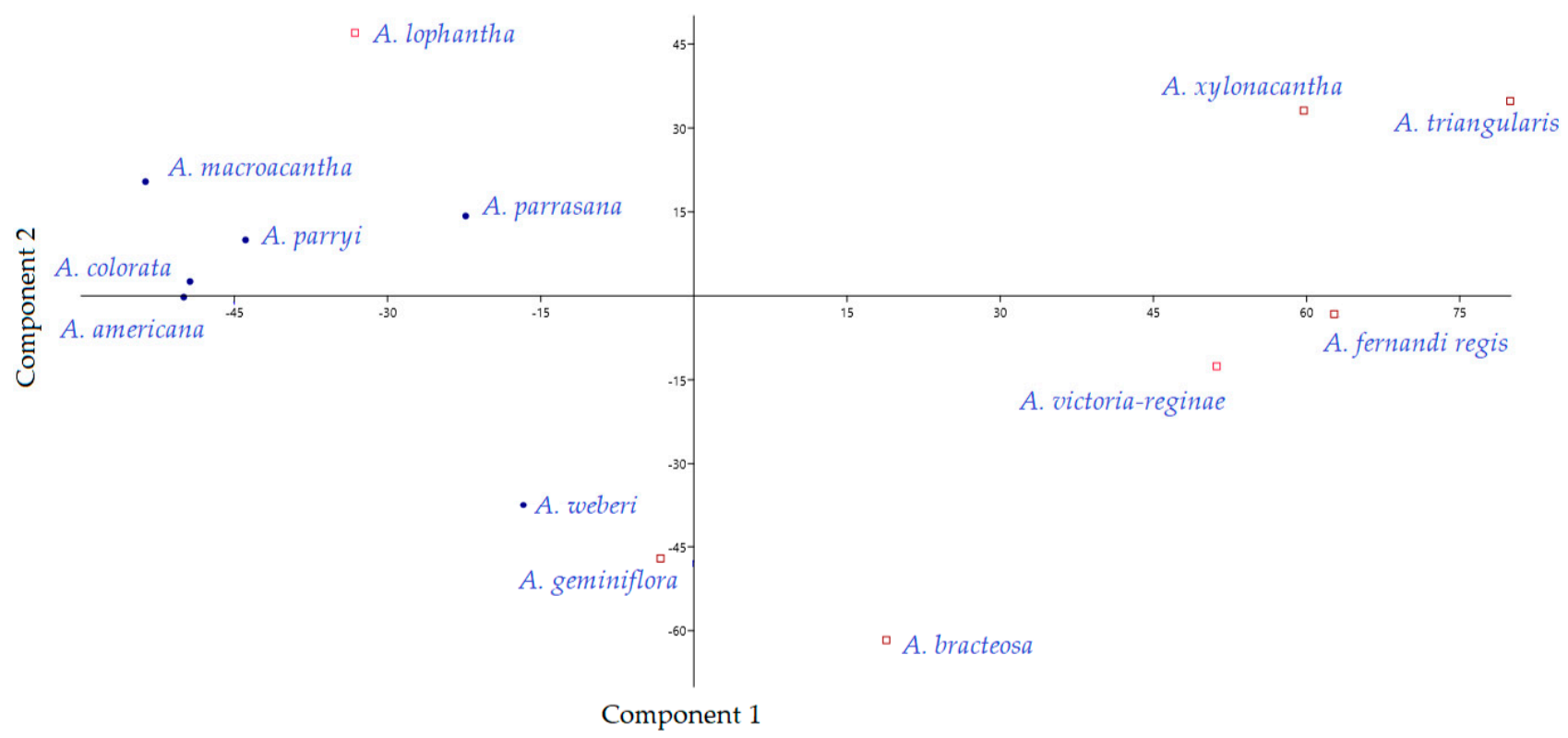

Figure 12. Principal Component Analysis of the different SFs from Agavaceae, taking into account all the structural characteristics obtained by the HMAI method and UPLC-QTOF-MSE ${ }^{\mathrm{E}}$ analysis.

It should be emphasized that the species $A$. weberi was located apart from the rest of the species in the same subgenus. This is because PC-2 shows the strong influence on the variable A12, A13, A20, which characterizes the saponins in group three. This type of saponin is present in many of the active SFs; however, because of its particularly high content in A. weberi, it could be clearly differentiated.

To sum up, SFs with a high proportion of saponins containing aglycones with a carbonyl group on the C-12 and an H-5 $\alpha$ configuration linked to a sugar chain of more than four sugar units are the most attractive for their potential application as bioherbicides. All of these belong to the subgenus Agave and were tested for phytotoxicity on the Standard Target Species (STS) [54]—Solanum lycopersicum (tomato), Lactuca sativa (lettuce) and Lepidium sativum (cress) - and on two harmful weed species for agricultural crops-Lolium perenne (perenne ryegrass) and Echinochloa crus-galli (barnyardgrass) (Figures 13 and 14). The most affected parameter was root length in all the species tested and also shoot lengths in the case of E. crus-galli. Moreover, species germination was not affected in all the cases. 
Regarding the STS bioassay, L. sativa - the dicotyledonous species that is most often used for allelopathy bioassays-was the most sensitive species [15,17].
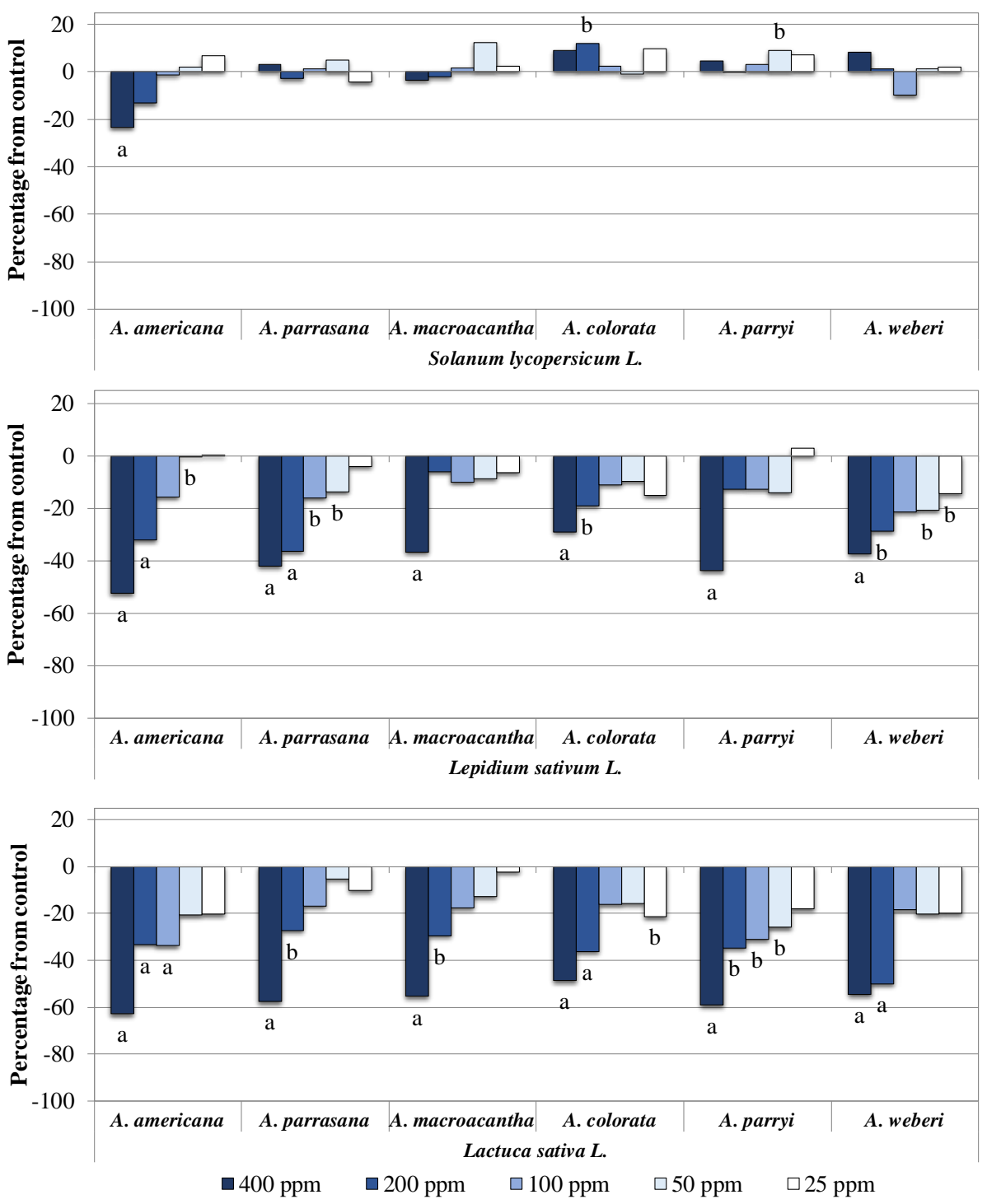

Figure 13. Effects of the saponin-rich fractions on STS. Statistical treatment of the data was carried out by Welch's test. Values are expressed as the percentage difference from the control. The absence of a letter indicates $p>0.05$; (a) denotes values significantly different from control at $p<0.01$ and (b) values significantly different at $0.01<p<0.05$.

This is in agreement with previous literature reports on these kinds of compounds [16]. Root growth inhibition values higher than $50 \%$ were achieved at the highest concentration (400 ppm) of every one of the SFs. It is worth noting that no activity on tomato was observed by any of the SFs tested; however, good activity profiles were obtained on weed species. Regarding their phytotoxicity on weed species, E. crus-galli was the most affected species with $\mathrm{IC}_{50}$ values lower than $80 \mathrm{ppm}$ for all the SFs evaluated, which were better values than those displayed by the commercial herbicide Logran ${ }^{\circledR}$, against both root and shoot lengths (Table 4). In order to determine the phytotoxicity levels shown by the different saponinrich fractions, a cluster analysis including all the species evaluated (STS and weeds) was performed (Figure 15). The saponin-rich fraction from A. americana exhibited the most potent phytotoxic capacity amongst all the SFs. 


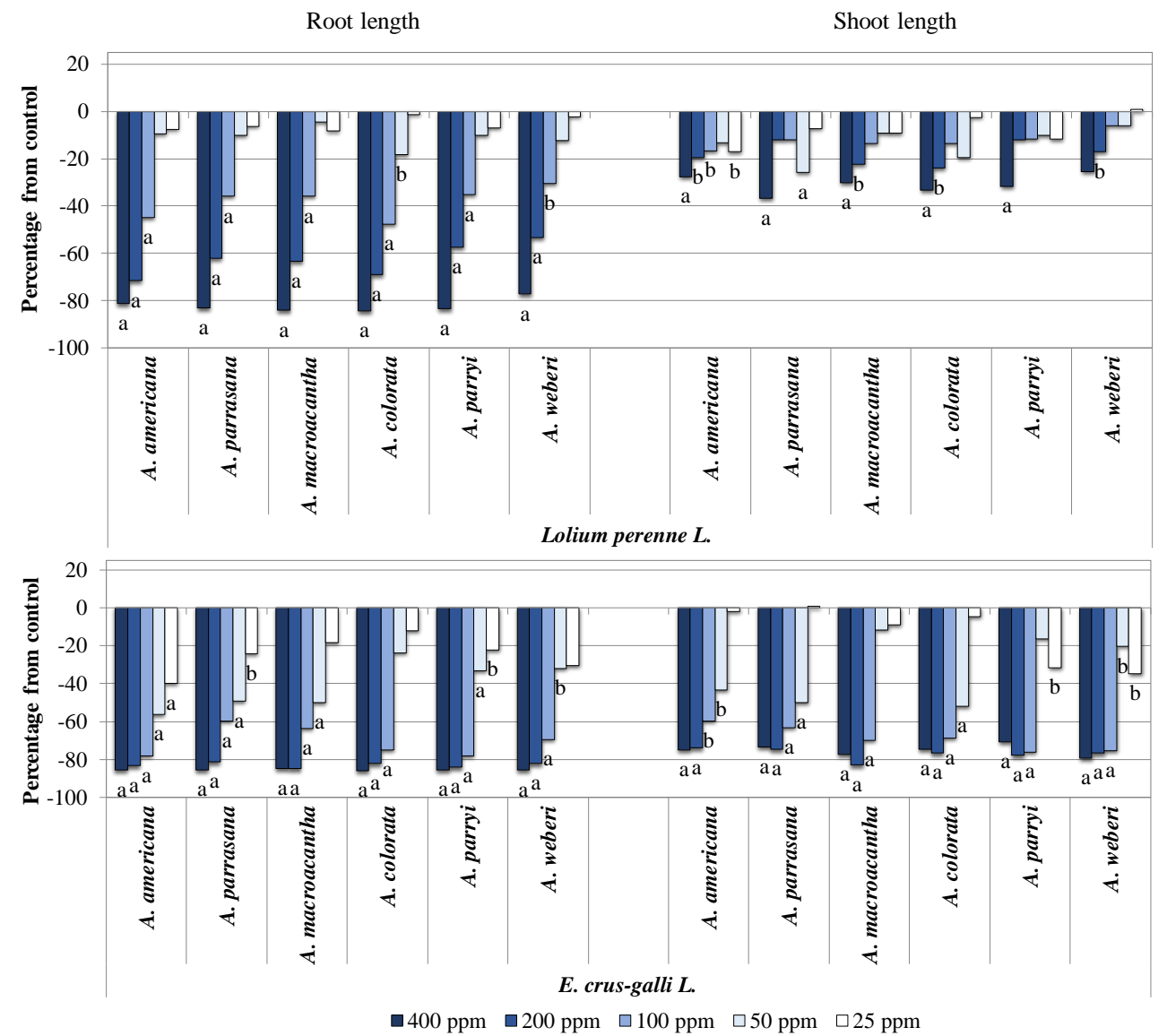

Figure 14. Effects of the saponin-rich fractions on weed species. Statistical treatment of the data was carried out by Welch's test. Values are expressed as percentage difference from control. The absence of a letter indicates $p>0.05$; (a) denotes values significantly different from control at $p<0.01$ and (b) values significantly different at $0.01<p<0.05$.

It should be highlighted that E. crus-galli affects transplanted tomatoes and that L. perenne directly affects planted tomatoes [55]. These results support the potential application of saponin-rich fractions as natural herbicides for the control of these weeds in tomato fields.

The SFs from all the species in the subgenus Agave exhibited some selective phytotoxic activity against weeds. In this sense, the saponins from the leaves of $A$. americana, as well as other species of the same subgenus, such as $A$. tequilana, $A$. salmiana, A. angustifolia, A. furcroydes, A. hookeri, A. inaequidens, A. marmorata or A. atrovirens [56,57], are already cultivated to produce distilled or non-distilled alcoholic beverages. The saponins from the leaves of these species could be a potential source of ecoherbicides. 
Table 4. $\mathrm{IC}_{50}$ values of all the saponin-rich fractions tested on the STS and weed bioassays.

\begin{tabular}{|c|c|c|c|c|c|}
\hline \multirow{2}{*}{$\begin{array}{l}\text { Species } \\
\text { Evaluated }\end{array}$} & \multirow{2}{*}{ Saponin-Rich Fraction } & \multicolumn{2}{|c|}{ Root } & \multicolumn{2}{|c|}{ Shoot } \\
\hline & & $\mathrm{IC}_{50}$ & $\mathbf{R}^{2}$ & $\mathrm{IC}_{50}$ & $\mathbf{R}^{2}$ \\
\hline \multicolumn{6}{|l|}{ STS species } \\
\hline \multirow{7}{*}{ L. sativum L. } & A. americana & 349.4 & 0.9955 & - & - \\
\hline & A. parrasana & - & - & - & - \\
\hline & A. macroacantha & - & - & - & - \\
\hline & A. colorata & - & - & - & - \\
\hline & A. parryi & - & - & - & - \\
\hline & A. weberi & - & - & - & - \\
\hline & $\operatorname{Logran}^{\circledR}$ & - & - & - & - \\
\hline \multirow{7}{*}{ L. sativa $L$. } & A. americana & 318.9 & 0.9711 & - & - \\
\hline & A. parrasana & 364.1 & 0.9917 & - & - \\
\hline & A. macroacantha & 368.1 & 0.9944 & - & - \\
\hline & A. colorata & 548.1 & 0.9734 & - & - \\
\hline & A. parryi & 361.9 & 0.9850 & - & - \\
\hline & A. weberi & 331.5 & 0.9623 & - & - \\
\hline & $\operatorname{Logran}^{\circledR}$ & - & - & - & - \\
\hline \multicolumn{6}{|l|}{ Weed species } \\
\hline \multirow{7}{*}{ L. perenne L. } & A. americana & 117.0 & 0.9875 & - & - \\
\hline & A. parrasana & 147.6 & 0.9978 & - & - \\
\hline & A. macroacantha & 147.9 & 0.9918 & - & - \\
\hline & A. colorata & 110.0 & 0.9945 & - & - \\
\hline & A. parryi & 158.6 & 0.9968 & - & - \\
\hline & A. weberi & 176.5 & 0.9993 & - & - \\
\hline & $\operatorname{Logran}^{\circledR}$ & 61.56 & 0.9920 & 134.7 & 0.9928 \\
\hline \multirow{7}{*}{ E. crus-galli L. } & A. americana & 34.88 & 0.9924 & 66.82 & 0.9499 \\
\hline & A. parrasana & 59.54 & 0.9924 & 49.55 & 0.9248 \\
\hline & A. macroacantha & 55.54 & 0.9857 & 76.83 & 0.9692 \\
\hline & A. colorata & 68.04 & 0.9793 & 44.58 & 0.9407 \\
\hline & A. parryi & 58.62 & 0.9721 & 70.20 & 0.8630 \\
\hline & A. weberi & 64.74 & 0.9753 & 69.19 & 0.8960 \\
\hline & Logran ${ }^{\circledR}$ & - & - & - & - \\
\hline
\end{tabular}

Cluster Analysis

STS and weed bioassay

Saponin-rich fractions

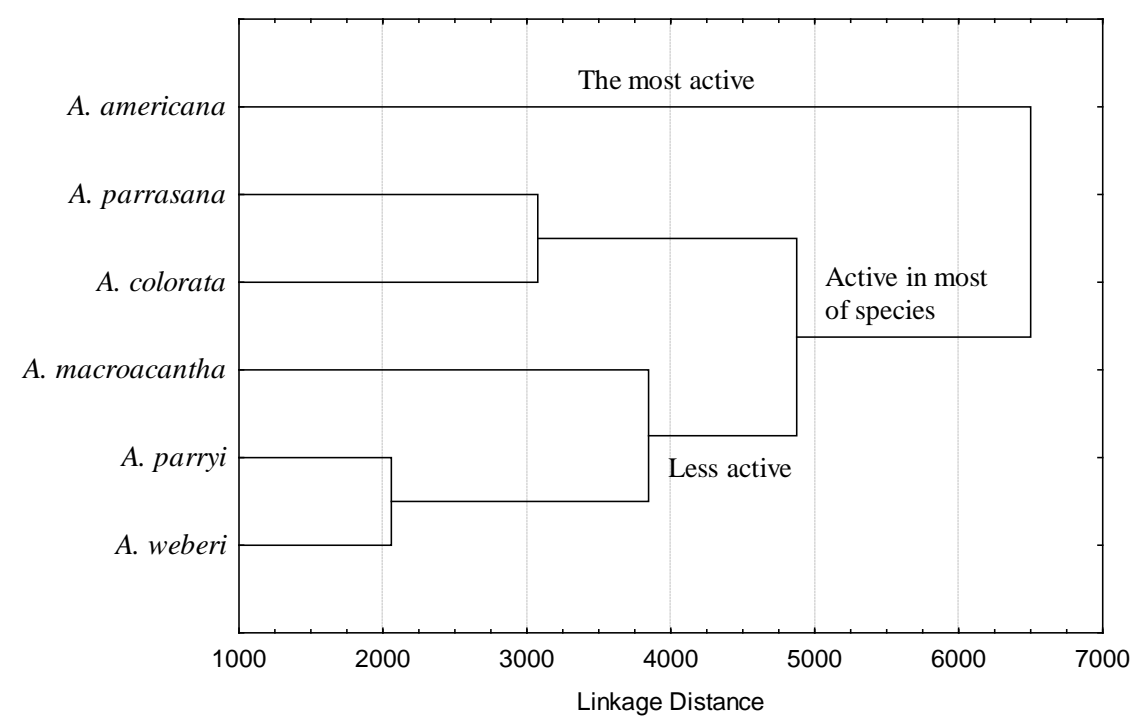

Figure 15. Cluster analysis of the saponin-rich fractions tested on the STS and weed species. 


\section{Conclusions}

A successful extraction method was obtained to get the crude saponin extracts. The crude saponin extract obtained by this method showed similar yields and bioactivities on etiolated wheat coleoptile bioassays than that obtained through the traditional method.

A comprehensive study of the $13 \mathrm{SFs}$ from the different Agave spp. have led to the identification of 20 aglycones through the information obtained by the HMAI method and UPLC-MS. Different isomers, such as the epimeric spirostane saponins on C-5 or on C-25, were successfully distinguished. The combination of these two techniques provide a valuable tool for the identification of the major aglycones in SFs without the need for isolation or hydrolysis of the saponins. On the other hand, the SFs that mainly contain saponins with a sugar chain length higher than four units, showed the best activity profiles on the wheat coleoptile bioassay.

It is also worth mentioning that the SFs from the subgenus Agave were proven to exhibit phytotoxic activity levels that render them as suitable for the effective control of harmful weeds.

These findings represent a possible lead for the development of natural herbicides through the use of these SFs without any further purification procedures to get the pure compounds, which would contribute to diminish the undesirable effects of synthetic herbicides.

Supplementary Materials: The following are available online at https:/ / www.mdpi.com/article/10 .3390 / agronomy11122404/s1, Table S1. Extraction experiments for optimization. Tables S2 and S3. HMAI Table of ${ }^{13} \mathrm{C}$ NMR chemical shifts for doublets and singlets. Table S4. UPLC-QTOF/MS ${ }^{\mathrm{E}}$ data corresponding to a SFs of Agave species. Table S5. Correlations between methyl groups and nearby carbons observed in the HMBC spectrum of the SFs of Agave species and HMAI interpretation. Figures S1 and S2. HMAI Flowchart of doblets and singlets. Figures S3-S5. ${ }^{1} \mathrm{H}$ NMR spectra of the four SFs discarded; from subgenus Agave and Littaea. Figures S6-S18. HMBC of SPs of Agave. Certificate of plants origin from Desert City company.

Author Contributions: Conceptualization, A.M.S.; methodology, A.G.D. and A.M.S.; investigation, A.G.D., J.B. and A.M.S.; data curation, A.G.D. and A.M.S.; writing-original draft preparation, A.G.D., J.B. and A.M.S.; writing-review and editing, A.G.D. and A.M.S.; supervision, A.M.S. and F.A.M.; project administration, F.A.M.; funding acquisition, F.A.M. All authors have read and agreed to the published version of the manuscript.

Funding: This research was funded by the Agencia Estatal de Investigación, Ministerio de Ciencia e Innovacion, grant number PID2020-115747RB-I00/AEI/10.13039/501100011033, Spain.

Acknowledgments: The authors thank the Desert City company (Madrid, Spain) for supplying the plant material and FITÓ S.A. (Barcelona, Spain) for providing seeds for the bioassays. Moreover, the authors express their thankfulness to Juan Miguel Duarte and Emiliano de Miguel from Servicios Centrales de Investigación Científica y Tecnológica (University of Cádiz).

Conflicts of Interest: The authors declare no conflict of interest.

\section{References}

1. Macías, F.A.; Durán, A.G.; Molinillo, J.M.G. Allelopathy: The Chemical Language of Plants. In Progress in the Chemistry of Organic Natural Products; Kinghorn, A.D., Falk, H., Gibbond, S., Kobayashi, J., Asakawa, Y., Liu, J.K., Eds.; Springer Nature: Cham, Switzerland, 2020; Volume 112, pp. 1-84, ISBN 9783030529659.

2. Ahmed, H.M. Phytochemical screening, total phenolic content and phytotoxic activity of corn (Zea mays) extracts against some indicator species. Nat. Prod. Res. 2018, 32, 714-718. [CrossRef]

3. Dai, Z.; Wang, J.; Ma, X.; Sun, J.; Tang, F. Laboratory and Field Evaluation of the Phytotoxic Activity of Sapindus mukorossi Gaertn Pulp Extract and Identification of a Phytotoxic Substance. Molecules 2021, 26, 1318. [CrossRef] [PubMed]

4. Zaynab, M.; Sharif, Y.; Abbas, S.; Afzal, M.Z.; Qasim, M.; Khalofah, A.; Ansari, M.J.; Khan, K.A.; Tao, L.; Li, S. Saponin toxicity as key player in plant defense against pathogens. Toxicon 2021, 193, 21-27. [CrossRef]

5. Simonet, A.M.; Durán, A.G.; Pérez, A.J.; Macías, F.A. Features in the NMR spectra of the aglycones of Agave spp. saponins. HMBC method for aglycone identification (HMAI). Phytochem. Anal. 2021, 32, 38-61. [CrossRef] [PubMed]

6. Ambreen, A.; Dastagir, G.; Bakht, J.; Adil, M. Phytotoxic, insecticidal and cytotoxic activities of Ziziphus mauritiana var. Spontanea Edgew. and Oenothera biennis L. Pak. J. Bot. 2020, 52, 2191-2195. [CrossRef] 
7. Ullah, R.; Bakht, J.; Shafi, M. Phytochemical analysis, phytotoxic and insecticidal activities of medicinally important Periploca hydaspidis. Pak. J. Pharm. Sci. 2018, 31, 841-849. [PubMed]

8. Begum, K.; Abbas, S.; Mushtaq, N.; Khan, S.U.; Parveen, I.; Ur Rahman, H.J.; Mahmood, S. Phytochemical screening and biological activities of Bromus pectinatus Thunb. Pak. J. Pharm. Sci. 2021, 34, 151-156. [CrossRef]

9. Gris, D.; Boaretto, A.G.; Marques, M.R.; Damasceno-Junior, G.A.; Carollo, C.A. Secondary metabolites that could contribute to the monodominance of Erythrina fusca in the Brazilian Pantanal. Ecotoxicology 2019, 28, 1232-1240. [CrossRef]

10. Mangao, A.M.; Arreola, S.L.B.; San Gabriel, E.V.; Salamanez, K.C. Aqueous extract from leaves of Ludwigia hyssopifolia (G. Don) Exell as potential bioherbicide. J. Sci. Food Agric. 2020, 100, 1185-1194. [CrossRef]

11. Pérez, A.J.; Simonet, A.M.; Pecio, Ł.; Kowalczyk, M.; Calle, J.M.; Macías, F.A.; Oleszek, W.; Stochmal, A. Triterpenoid saponins from the aerial parts of Trifolium argutum Sol. and their phytotoxic evaluation. Phytochem. Lett. 2015, 13, 165-170. [CrossRef]

12. Scognamiglio, M.; D’Abrosca, B.; Fiumano, V.; Chambery, A.; Severino, V.; Tsafantakis, N.; Pacifico, S.; Esposito, A.; Fiorentino, A. Oleanane saponins from Bellis sylvestris Cyr. and evaluation of their phytotoxicity on Aegilops geniculata Roth. Phytochemistry 2012, 84, 125-134. [CrossRef] [PubMed]

13. Hernández-Carlos, B.; González-Coloma, A.; Orozco-Valencia, Á.U.; Ramírez-Mares, M.V.; Andrés-Yeves, M.F.; Joseph-Nathan, P. Bioactive saponins from Microsechium helleri and Sicyos bulbosus. Phytochemistry 2011, 72, 743-751. [CrossRef]

14. Stavropoulou, M.I.; Angelis, A.; Aligiannis, N.; Kalpoutzakis, E.; Mitakou, S.; Duke, S.O.; Fokialakis, N. Phytotoxic triterpene saponins from Bellis longifolia, an endemic plant of Crete. Phytochemistry 2017, 144, 71-77. [CrossRef]

15. Pérez, A.J.; Simonet, A.M.; Calle, J.M.; Pecio, Ł.; Guerra, J.O.; Stochmal, A.; Macías, F.A. Phytotoxic steroidal saponins from Agave offoyana leaves. Phytochemistry 2014, 105, 92-100. [CrossRef] [PubMed]

16. Calle, J.M.; Pérez, A.J.; Simonet, A.M.; Guerra, J.O.; Macías, F.A. Steroidal Saponins from Furcraea hexapetala Leaves and Their Phytotoxic Activity. J. Nat. Prod. 2016, 79, 2903-2911. [CrossRef] [PubMed]

17. Pérez, A.J.; Calle, J.M.; Simonet, A.M.; Guerra, J.O.; Stochmal, A.; Macías, F.A. Bioactive steroidal saponins from Agave offoyana flowers. Phytochemistry 2013, 95, 298-307. [CrossRef] [PubMed]

18. Feitoza, R.B.B.; Varela, R.M.; Torres, A.; Molinillo, J.M.G.; Lima, H.R.P.; Moraes, L.F.D.; Da Cunha, M.; Macías, F.A. Evaluation of the Phytotoxicity of Urochloa humidicola Roots by Bioassays and Microscopic Analysis. Characterization of New Compounds. J. Agric. Food Chem. 2020, 68, 4851-4864. [CrossRef] [PubMed]

19. Segura, R.; Vásquez, G.; Colson, E.; Gerbaux, P.; Frischmon, C.; Nesic, A.; García, D.E.; Cabrera-Barjas, G. Phytostimulant properties of highly stable silver nanoparticles obtained with saponin extract from Chenopodium quinoa. J. Sci. Food Agric. 2020, 100, 4987-4994. [CrossRef]

20. Cheok, C.Y.; Salman, H.A.K.; Sulaiman, R. Extraction and quantification of saponins: A review. Food Res. Int. 2014, 59, 16-40. [CrossRef]

21. Durán, A.G.; Celaj, O.; Macías, F.A.; Simonet, A.M. Dereplication of Bioactive Spirostane Saponins from Agave macroacantha. J. Nat. Prod. 2021, 84, 2904-2913. [CrossRef]

22. Rial, C.; Varela, R.M.; Molinillo, J.M.G.; Bautista, E.; Hernández, A.O.; Macías, F.A. Phytotoxicity evaluation of sesquiterpene lactones and diterpenes from species of the Decachaeta, Salvia and Podachaenium genera. Phytochem. Lett. 2016, 18, 68-76. [CrossRef]

23. Durán, A.G.; Chinchilla, N.; Molinillo, J.M.; Macías, F.A. Influence of lipophilicity in O -acyl and O -alkyl derivatives of juglone and lawsone: A structure-activity relationship study in the search for natural herbicide models. Pest Manag. Sci. 2018, 74, 682-694. [CrossRef] [PubMed]

24. Castellano, D.; Macías, F.A.; Castellano, M.; Cambronero, R.M. FITOMED (automated system for measurement of variable lenghts). Spain Patent P9901565, 15 June 2001.

25. Yokosuka, A.; Yoshihiro, M.; Kuroda, M.; Sashida, Y. A new steroidal saponin from the leaves of Agave americana. Planta Med. 2000, 66, 393-396. [CrossRef] [PubMed]

26. Jin, J.M.; Liu, X.K.; Yang, C.R. Three new hecogenin glycosides from fermented leaves of Agave americana. J. Asian Nat. Prod. Res. 2003, 5, 95-103. [CrossRef]

27. Xu, H.-N.; He, C.-H. Extraction of isoflavones from stem of Pueraria lobata (Willd.) Ohwi using n-butanol/water two-phase solvent system and separation of daidzein. Sep. Purif. Technol. 2007, 56, 85-89. [CrossRef]

28. Urbina, C.J.F.; Casas, A.; Martínez-Díaz, Y.; Santos-Zea, L.; Gutiérrez-Uribe, J.A. Domestication and saponins contents in a gradient of management intensity of agaves: Agave cupreata, A. inaequidens and A. hookeri in central Mexico. Genet. Resour. Crop Evol. 2018, 65, 1133-1146. [CrossRef]

29. Leal-Díaz, A.M.; Santos-Zea, L.; Martínez-Escobedo, H.C.; Guajardo-Flores, D.; Gutiérrez-Uribe, J.A.; Serna-Saldivar, S.O. Effect of Agave americana and Agave salmiana Ripeness on Saponin Content from Aguamiel (agave Sap). J. Agric. Food Chem. 2015, 63, 3924-3930. [CrossRef]

30. Santos-Zea, L.; Rosas-Pérez, A.M.; Leal-Díaz, A.M.; Gutiérrez-Uribe, J.A. Variability in Saponin Content, Cancer Antiproliferative Activity and Physicochemical Properties of Concentrated Agave Sap. J. Food Sci. 2016, 81, H2069-H2075. [CrossRef]

31. Puente-Garza, C.A.; García-Lara, S.; Gutiérrez-Uribe, J.A. Enhancement of saponins and flavonols by micropropagation of Agave salmiana. Ind. Crops Prod. 2017, 105, 225-230. [CrossRef]

32. Puente-Garza, C.A.; Meza-Miranda, C.; Ochoa-Martínez, D.; García-Lara, S. Effect of in vitro drought stress on phenolic acids, flavonols, saponins, and antioxidant activity in Agave salmiana. Plant Physiol. Biochem. 2017, 115, 400-407. [CrossRef] 
33. Puente-Garza, C.A.; Espinosa-Leal, C.A.; García-Lara, S. Steroidal Saponin and Flavonol Content and Antioxidant Activity during Sporophyte Development of Maguey (Agave salmiana). Plant Foods Hum. Nutr. 2018, 73, 287-294. [CrossRef]

34. Figueroa, L.; Santos-Zea, L.; Escalante, A.; Gutiérrez-Uribe, J. Mass Spectrometry-Based Metabolomics of Agave Sap (Agave salmiana) after Its Inoculation with Microorganisms Isolated from Agave Sap Concentrate Selected to Enhance Anticancer Activity. Sustainability 2017, 9, 2095. [CrossRef]

35. Scott Gentry, H. Agaves of Continental North America, 3rd ed.; University of Arizona Press: Tucson, AZ, USA, 2004; ISBN 0816523959.

36. Sidana, J.; Singh, B.; Sharma, O.P. Saponins of Agave: Chemistry and bioactivity. Phytochemistry 2016, 130, 22-46. [CrossRef] [PubMed]

37. Yokosuka, A.; Sano, T.; Hashimoto, K.; Sakagami, H.; Mimaki, Y. Steroidal Glycosides from Furcraea foetida and Their Cytotoxic Activity. Chem. Pharm. Bull. 2009, 57, 1161-1166. [CrossRef] [PubMed]

38. Huang, X.; Kong, L. Steroidal saponins from roots of Asparagus officinalis. Steroids 2006, 71, 171-176. [CrossRef]

39. Mimaki, Y.; Nakamura, O.; Sashida, Y.; Nikaido, T.; Ohmoto, T. Steroidal saponins from the bulbs of Triteleia lactea and their inhibitory activity on cyclic AMP phosphodiesterase. Phytochemistry 1995, 38, 1279-1286. [CrossRef]

40. Mimaki, Y.; Kanmoto, T.; Kuroda, M.; Sashida, Y.; Nishino, A.; Satomi, Y.; Nishino, H. Steroidal Saponins from the Underground Parts of Hosta longipes and Their Inhibitory Activity on Tumor Promoter-Induced Phospholipid Metabolism. Chem. Pharm. Bull. 1995, 43, 1190-1196. [CrossRef]

41. Yokosuka, A.; Jitsuno, M.; Yui, S.; Yamazaki, M.; Mimaki, Y. Steroidal Glycosides from Agave utahensis and Their Cytotoxic Activity. J. Nat. Prod. 2009, 72, 1399-1404. [CrossRef]

42. Qu, L.; Ruan, J.; Wu, S.; Huang, P.; Yan, J.; Yu, H.; Zhang, Y.; Wang, T. Separation and Bioactive Assay of 25R/S-Spirostanol Saponin Diastereomers from Yucca schidigera Roezl (Mojave) Stems. Molecules 2018, 23, 2562. [CrossRef]

43. Qu, L.; Wang, J.; Ruan, J.; Yao, X.; Huang, P.; Wang, Y.; Yu, H.; Han, L.; Zhang, Y.; Wang, T. Spirostane-Type Saponins Obtained from Yucca schidigera. Molecules 2018, 23, 167. [CrossRef]

44. González, M.; Zamilpa, A.; Marquina, S.; Navarro, V.; Alvarez, L. Antimycotic spirostanol saponins from Solanum hispidum leaves and their structure-activity relationships. J. Nat. Prod. 2004, 67, 938-941. [CrossRef]

45. Macías, F.A.; Guerra, J.O.; Simonet, A.M.; Pérez, A.J.; Nogueiras, C. Characterization of three saponins from a fraction using 1D DOSY as a solvent signal suppression tool. Agabrittonosides E-F. Furostane Saponins from Agave brittoniana Trel. spp. Brachypus. Magn. Reson. Chem. 2010, 48, 350-355. [CrossRef] [PubMed]

46. Yang, Q.-X.; Xu, M.; Zhang, Y.-J.; Li, H.-Z.; Yang, C.-R. Steroidal saponins from Disporopsis pernyi. Helv. Chim. Acta 2004, 87, 1248-1253. [CrossRef]

47. Mina, S.; Melek, F.R.; Abdel-khalik, S.M.; El-Shaarawy, F.S.; Eskander, J. Pharmacological Activities of Agave seemanniana and Isolation of Three Steroidal Saponins. Eur. J. Med. Plants 2014, 4, 271-283. [CrossRef]

48. Agrawal, P.K. Assigning stereodiversity of the 27-Me group of furostane-type steroidal saponins via NMR chemical shifts. Steroids 2005, 70, 715-724. [CrossRef]

49. Macías, F.A.; Guerra, J.O.; Simonet, A.M.; Nogueiras, C.M. Characterization of the fraction components using 1D TOCSY and 1D ROESY experiments. Four new spirostane saponins from Agave brittoniana Trel. spp. Brachypus. Magn. Reson. Chem. 2007, 45, 615-620. [CrossRef] [PubMed]

50. Ohtsuki, T.; Koyano, T.; Kowithayakorn, T.; Sakai, S.; Kawahara, N.; Goda, Y.; Yamaguchi, N.; Ishibashi, M. New chlorogenin hexasaccharide isolated from Agave fourcroydes with cytotoxic and cell cycle inhibitory activities. Bioorgan. Med. Chem. 2004, 12, 3841-3845. [CrossRef]

51. Monterrosas-Brisson, N.; Arenas Ocampo, M.L.; Jiménez-Ferrer, E.; Jiménez-Aparicio, A.R.; Zamilpa, A.; Gonzalez-Cortazar, M.; Tortoriello, J.; Herrera-Ruiz, M. Anti-inflammatory activity of different Agave plants and the compound Cantalasaponin-1. Molecules 2013, 18, 8136-8146. [CrossRef] [PubMed]

52. Eskander, J.; Lavaud, C.; Harakat, D. Steroidal saponins from the leaves of Agave macroacantha. Fitoterapia 2010, 81, 371-374. [CrossRef]

53. Yu, H.-S.; Zou, P.; Song, X.-B.; Kang, L.-P.; Liu, Y.-X.; Pang, X.; Zhang, J.; Fu, J.; Zhao, Y.; Xiong, C.-Q.; et al. Two new steroidal saponins from the fresh leaves of Agave sisalana. Helv. Chim. Acta 2011, 94, 1351-1358. [CrossRef]

54. Macias, F.A.; Castellano, D.; Molinillo, J.M.G. Search for a standard phytotoxic bioassay for allelochemicals. selection of standard target species. J. Agric. Food Chem. 2000, 48, 2512-2521. [CrossRef] [PubMed]

55. Rial, C.; Gómez, E.; Varela, R.M.; Molinillo, J.M.G.; Macías, F.A. Ecological Relevance of the Major Allelochemicals in Lycopersicon esculentum Roots and Exudates. J. Agric. Food Chem. 2018, 66, 4638-4644. [CrossRef] [PubMed]

56. Valdivieso Solís, D.G.; Vargas Escamilla, C.A.; Mondragón Contreras, N.; Galván Valle, G.A.; Gilés-Gómez, M.; Bolívar, F.; Escalante, A. Sustainable Production of Pulque and Maguey in Mexico: Current Situation and Perspectives. Front. Sustain. Food Syst. 2021, 5, 226. [CrossRef]

57. Álvarez-Chávez, J.; Villamiel, M.; Santos-Zea, L.; Ramírez-Jiménez, A.K. Agave By-Products: An Overview of Their Nutraceutical Value, Current Applications, and Processing Methods. Polysaccharides 2021, 2, 44. [CrossRef] 